\title{
REDUCING BUMPS AT PAVEMENT-BRIDGE INTERFACE
}

\author{
by
}

Amar Shukla

Submitted in Partial Fulfillment of the Requirements

for the Degree of

Master of Science in Engineering

in the

Civil and Environmental Engineering

Program

Youngstown State University

June 2011

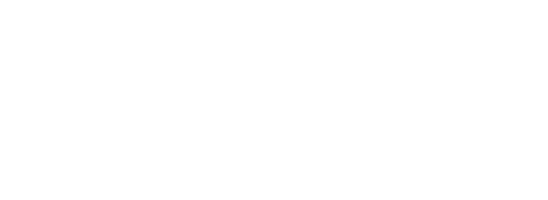




\section{Amar Shukla}

I hereby release this thesis to the public. I understand this thesis will be made available from the OhioLINK ETD Center and the Maag Library Circulation Desk for public access. I also authorize this University or other individuals to make copies of this thesis as needed for scholarly research.

Signature:

Amar Shukla, Student

Date

Approvals:

Dr. Anwarul Islam, Thesis Advisor

Date

Dr. Scott C. Martin, Committee Member

Date

Dr. Daniel H. Suchora, Committee Member

Date

Dr. Peter J. Kasvinsky, Dean of Graduate Studies

Date 


\section{ABSTRACT}

This report addresses the causes and long-term solutions to the bumps that commonly develop at bridge/approach slab and/or approach slab/pavement interfaces. Moment capacities and applied moments of approach slabs for seven different State Departments of Transportation (DOTs) were determined using MathCAD, and compared. The value of internal moment capacity of the Ohio Department of Transportation (ODOT) approach slab was found to be greater than the value of applied moment capacity, indicating that a new approach slab would not fail even if soil support were lost. A 3-D finite element analysis (FEA) was performed using ALGOR to find the stresses and deflections for a new approach slab of $25 \mathrm{ft}$ slab length under extreme HL-93 truck static loading, using ODOT design recommendations. Maximum deflection was predicted to be 0.19 in with soil support and 1.34 in without soil support. Repetitive loading may cause long-term damage to approach slabs when soil support is lost.

Laboratory tests for Sieve analysis, Liquid limit and Plastic limit were also performed on soil samples collected from one bridge site without a significant bump and four bridge sites with significant bumps around the greater Youngstown, Ohio, area. The results show that settlement of approach slabs was greater, and bumps more severe, for soils with larger percentages of silt and clay. This study indicates that efforts to reduce bumps at the pavement-bridge interface should focus on geotechnical factors and maintaining proper soil support under approach slabs. 


\section{DEDICATION}

To my parents, Surendra P. Shukla and Lata R. Shukla -

without your love and support, this work would never have materialized. 


\section{ACKNOWLEDGEMENTS}

I would like to extend my sincere appreciation and gratitude to my advisor, Dr. Anwarul Islam, for his advisement, guidance, and endless editing efforts to complete this research. I would also like to express my cordial appreciation to Dr. Scott C. Martin and Dr. Daniel H. Suchora for their help, suggestions and encouragement during the course of this research. I would also like to thank the committee members for serving on my thesis defense committee. I gratefully acknowledge the help provided by Dr. Ann G. Harris and Dr. Cynthia Hirtzel. I sincerely express my gratitude to YSU Center for Transportation and Materials Engineering for funding this research. Finally, I would like to thank Dr. Shakir Husain, friends and family for their support and inspiration. 


\section{TABLE OF CONTENTS}

PAGE

ABSTRACT iii

DEDICATION IV iv

ACKNOWLEDGEMENTS V V

TABLE OF CONTENTS Vi

LIST OF FIGURES viii

LIST OF TABLES IX ix

CHAPTER

1. INTRODUCTION 1

1.1 Definition of Bump 1

1.2 Background 1

1.3 Goals and Objectives 3

1.4 Research Significance 4

2. LITERATURE REVIEW 6

3. GEOTECHNICAL INVESTIGATIONS USING FIELD DATA 15

$\begin{array}{ll}3.1 \text { Methods } & 15\end{array}$

3.2 Summary of Results 16

3.3 Detailed Laboratory Data and Photos 19

4. STRUCTURAL ANALYSIS OF APPROACH SLABS 30

4.1 Hand Calculations $\quad 30$

$\begin{array}{ll}\text { 4.2 Finite Element Analysis } & 31\end{array}$

5. DISCUSSION OF RESULTS 42 


\section{TABLE OF CONTENTS (CONTINUED)}

PAGE

6. CONCLUSIONS AND RECOMMENDATIONS 46

$\begin{array}{ll}\text { REFERENCES } & 48\end{array}$

$\begin{array}{ll}\text { APPENDIX A } & 50\end{array}$

$\begin{array}{ll}\text { APPENDIX B } & 52\end{array}$

APPENDIX C $\quad 55$ 


\section{LIST OF FIGURES}

FIGURE

PAGE

1.1 Bump mechanism and behavior of approach slab due to

3 pavement settlement

2.1 Schematic of an integral abutment system with sleeper slab 9

2.2 Various factors that can result in the formation of bumps $\quad 11$

3.1 Pictures of bumps at Bridge No. COL 302578

3.2 Pictures of bumps at Bridge No. COL 302667

3.3 Pictures of bumps at Bridge No. COL 112L 24

3.4 Pictures of bumps at Bridge No. COL 30267026

3.5 Pictures of bumps at Bridge No. COL 303182

4.1 $\quad$ FE Model A of approach slab with soil 32

4.2 FE Model B of approach slab without soil 33

4.3 Cross-section of approach slab models 34

4.4A FE Model A showing results on displacement 37

4.4B FE Model B showing results on displacement 38

4.5A FE Model A showing results on stresses in concrete 39

4.5B FE Model B showing results on compressive stresses $\quad 40$ in concrete

4.5C FE Model B showing results on stresses in bottom 41 reinforcement

5.1 Formation of bump due to failure of approach slab 42

5.2 Bump formation due to excessive settlement of sleeper slab 43

C.1 Cross-section of approach slab models 55 


\section{LIST OF TABLES}

TABLE

PAGE

$\begin{array}{lll}2.1 & \text { Refined IRI approach slab system (IRIS) }\end{array}$

$\begin{array}{lll}3.1 & \text { Results obtained on soil samples from five bridges in } & 17\end{array}$ Columbiana County, $\mathrm{OH}$

3.2 Ground improvement methods based on soil type 18

3.3 Sieve analysis of soil under approach slab of Bridge No. 20 COL 302578

3.4 Liquid limit test of soil under approach slab of Bridge No. 21 COL 302578

3.5 Plastic limit test of soil under approach slab of Bridge No. 21 COL 302578

3.6 Sieve analysis of soil under approach slab of Bridge No. COL 302667

3.7 Liquid limit test of soil under approach slab of Bridge No. 22 COL 302667

3.8 Plastic limit test of soil under approach slab of Bridge No. 23 COL 302667

3.9 Sieve analysis of soil under approach slab of Bridge No. 23 COL $112 \mathrm{~L}$

3.10 Liquid limit test of soil under approach slab of Bridge No. 24 COL $112 \mathrm{~L}$

3.11 Plastic limit test of soil under approach slab of Bridge No. 25 COL $112 \mathrm{~L}$

3.12 Sieve analysis of soil under approach slab of Bridge No. 25 COL 302670

3.13 Liquid limit test of soil under approach slab of Bridge No. 26 COL 302670

3.14 Plastic limit test of soil under approach slab of Bridge No. COL 302670 


\section{LIST OF TABLES (CONTINUED)}

TABLE

PAGE

3.15 Sieve analysis of soil under approach slab of Bridge No.

COL 303182

3.16 Liquid limit test of soil under approach slab of Bridge No.

COL 303182

3.17 Plastic limit test of soil under approach slab of Bridge No.

COL 303182

4.1 Approach slab designs in different state DOTs

4.2 Properties of soil for FE model

A1 Reinforcement ratio of slab under differential settlement (adopted new design for Louisiana Department of Transportation and Development (LADOTD), $\mathrm{f}_{\mathrm{c}^{\prime}}=4000 \mathrm{psi}$ and $\mathrm{f}_{\mathrm{y}}=60,000 \mathrm{psi}$ )

A2 Design of reinforced beam (adopted new design for

LADOTD, $\mathrm{f}_{\mathrm{c}^{\prime}}=4000$ psi and $\left.\mathrm{f}_{\mathrm{s}}=60,000 \mathrm{psi}\right)$ 


\section{CHAPTER 1}

\section{INTRODUCTION}

\subsection{Definition of Bump}

Roadways and embankments are built on sub-grade foundation and compacted fill materials, respectively, that undergo load induced compression over time. The compression leads to settlements. The total settlement of a bridge is usually much smaller than the settlement of the roadway and/or adjoining embankment, which results in considerable degree of difference in the settlement at the intersection. Consequently, noticeable bumps develop at bridge ends.

Commonly, a bump can be defined as the differential settlement in the area between the bridge and approach slab. Stark et al. [1] conducted a survey of 1,181 bridges in the State of Illinois and suggested that the riders' discomfort across the bump was magnified if the approach gradient was in excess of 1/200. Regarding differential settlement at the pavement-bridge interface, Wahls [2] suggested that a differential settlement of $0.5 \mathrm{in}$. is likely to require maintenance. He also suggested a tolerable relative rotation (differential movement divided by the length over which the settlement occurs) of $1 / 250$ for continuous-span bridges and 1/200 for simply supported spans.

\subsection{Background}

Bridge bumps are the results of differential settlement between bridge and approach slab and/or between approach slab and pavement. To date no 
multifaceted set of engineering explanations have been developed. An extensive study of previous research work was conducted and different factors that can lead to the formation of bumps are discussed in the Literature Review (Chapter 2). Bumps can be formed due to the movement of soil underneath the approach slab. Bumps can also occur when the internal moment capacity of the approach slab is less than the applied moment. Bumps at the pavement-bridge interface reduce the riding comfort of a driver and al so create bad images of the state Departments of Transportation (DOTs) and ot her government agencies responsible for roads. Approach slabs are thus provided at the end of bridges for smooth transition of vehicles (Figure 1.1).

Bridge bumps are a major problem across the United States. The state DOTs spend a large portion of their maintenance budget for bump-related repairs every year. Briaud et al. [3] summarized that 150,000 bridges out of almost 600,000 bridges across United States, had bridge bumps that cost approximately $\$ 100$ million per year for repair (figures from mid-1990’s).

Approach slabs are placed at the end of bridges for the better transition of vehicles from a bridge to a pavement, or vice versa. When the soil beneath an approach slab loses contact, the slab bends down to a concave shape. Figure 1.1 shows the behavior of approach slab due to pavement settlement. Approach slab near the bridge is placed on a back wall, which is supported by foundations. The other end of the approach slab is placed on the pavement, or sometimes on a sleeper slab. A bump is formed when the backfill under the approach slab loses contact with it. It can also be caused due to structural reasons if the approach 
slab is designed insufficiently. Conditions become worse due to the combination of re-occurring soil settlement and continual impacts from vehicles running over the already created bump, if the problem is not fixed in a timely manner.

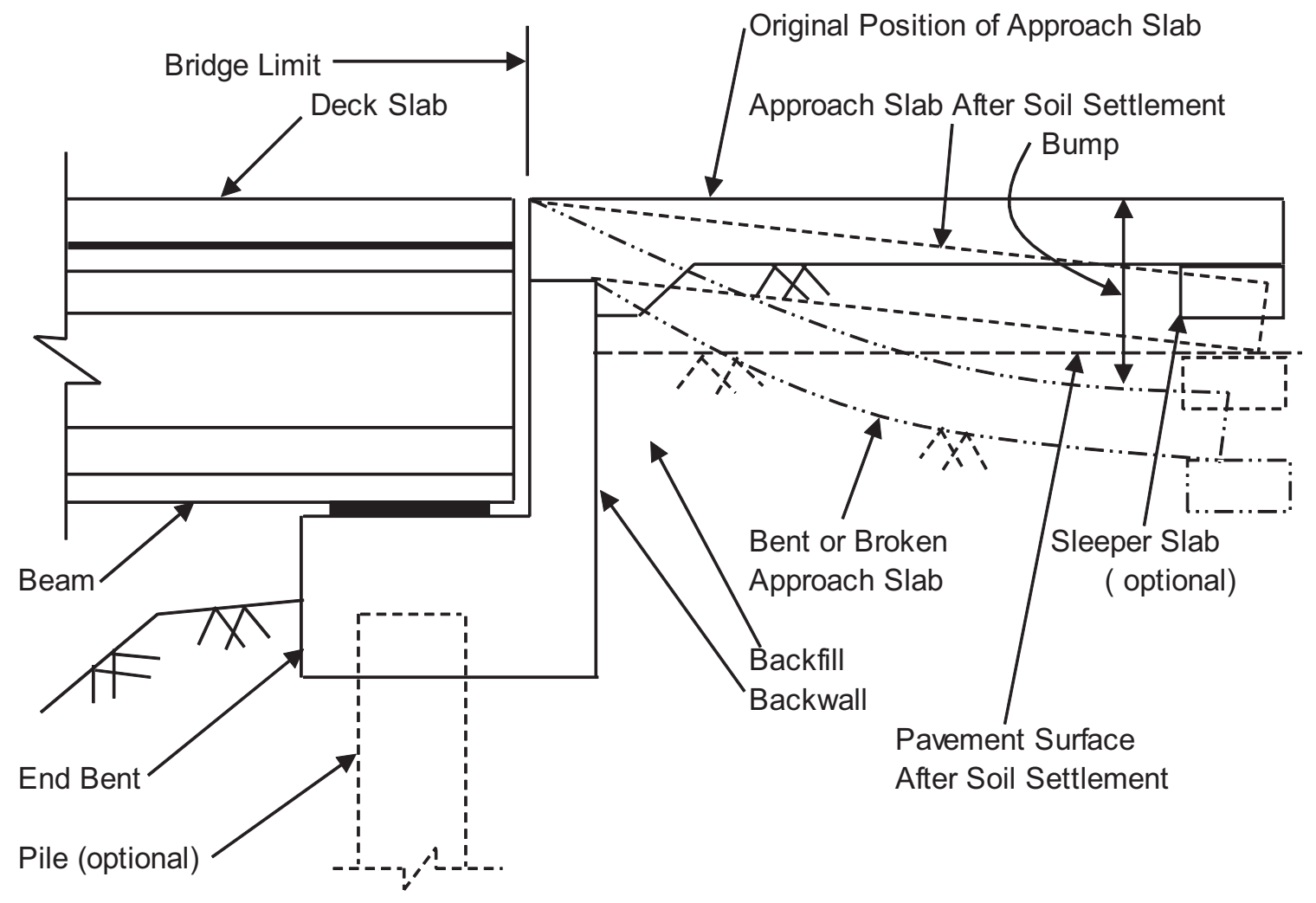

Figure 1.1 - Bump mechanism and behavior of approach slab due to pavement settlement.

\subsection{Goals and Objectives}

Research is needed to develop cost-efficient solutions for reducing bumps at the pavement-bridge interface in order to improve ride quality, decrease safety hazards, and minimize future maintenance costs. This study was designed to contribute to this broad goal. The objective of this project was to develop specifications and guidelines for the design and construction of approach slabs 
and adjoining embankments that may reduce bumps in the long run, and check the probable solutions for accuracy and effectiveness through structural analysis and design. This was accomplished by performing the following steps:

1. A number of bridges in Columbiana County, Ohio were visited, bump characteristics were noted and photographed, and soil samples from the site were collected and tested in the laboratory in order to evaluate geotechnical aspects of the design.

2. Various attributes of state DOT approach slab designs, such as slab length, thickness of slab, top and bottoms reinforcement and strength of concrete, were compiled and compared. Approach slab internal moment capacities were calculated for the various state DOT designs to determine if the present designs are adequate to withstand HL-93 truck loading.

3. A finite element model (FEM) of an Ohio Department of Transportation (ODOT) approach slab was created in ALGOR to determine the maximum applied moment under HL-93 truck loading.

4. The results of structural and geotechnical evaluations were combined to develop suggestions for reducing bumps at the roadway-bridge interface.

\subsection{Research Significance}

The research significance is as follows:

- Reduce maintenance cost for transportation department.

- Lane closures due to maintenance work can be avoided.

- Less traffic congestion by avoiding lane closures. 
- Smooth transition of vehicles from bridges to pavement.

- Decrease distraction for drivers.

- Safe ride for drivers.

- Improvement of public perception for transportation department.

- Propose a guideline for the construction of approach slabs. 


\section{CHAPTER 2}

\section{LITERATURE REVIEW}

Several previous studies have addressed the characterization and causes of bumps at the bridge-pavement interface. A review of this literature is presented to provide direction and background for the present study.

The quality of the road surface is determined by measuring the roughness of the road longitudinally, which is defined as International Roughness Index (IRI). Das et al. [4] calculated IRIs using a I aser profiler and represented graphically with IRI in $\mathrm{m} / \mathrm{km}$ on $\mathrm{Y}$-axis and distance in meters on X-axis. IRI was found to be higher at the ends of approach slabs [4]. The conditions of ninety approach slabs were studied and the IRI value was compared [4]. It was found that $4 \%$ of the slabs were in very good condition, $22 \%$ in good condition, and $33 \%$ in fair condition, $22 \%$ in poor condition and $19 \%$ in very poor condition. Das et al. [4] developed a new approach slab rating system, based on IRI System [5] (as shown in Table 2.1), to evaluate the approach slabs condition.

Table 2.1 - Refined IRI approach slab system (IRIS) [4]

\begin{tabular}{|c|c|}
\hline $\begin{array}{c}\text { IRI } \\
\text { Rating }\end{array}$ & Rating \\
\hline 0 to 3.9 & Very good \\
\hline 4.0 to 7.9 & Good \\
\hline 8.0 to 9.9 & Fair \\
\hline 10.0 to & Poor \\
11.9 & \\
\hline $\begin{array}{c}12 \text { and } \\
\text { above }\end{array}$ & Very poor \\
\hline
\end{tabular}


Puppala et al. [6] surveyed 25 districts in Texas and summarized the following causes for the settlement of approach slabs:

1. Consolidation settlement of foundation soil.

2. Poor compaction and consolidation of backfill material.

3. Poor drainage and soil erosion.

4. Types of bridge abutments.

5. Traffic volume.

6. Age of the approach slab.

7. Approach slab design.

8. Skewness of the bridge.

9. Seasonal temperature variations.

This research shows that settlement of approach slabs is often complex and may involve multiple parameters. Several other studies have described the main components of the bridge-highway interface and identified common problems that can lead to bump formation. A few of these are reviewed below.

Dupont and Allen [7] conducted a survey on 50 state highway agencies in the United States. Their study showed that only 31 states used approach slabs. Of the 31 states, only $14 \mathrm{~s}$ tates used the sleeper slabs. Figure 2.1 shows a schematic diagram of an integral abutment system of an a pproach pavement with sleeper slab. The purpose for a sleeper slab is to diminish the possibility of differential settlement by letting the approach slab settle with the embankment. This prevents the formation of a bump at the approach slab-pavement interface to some extent. If the sleeper slab is designed insufficiently, it may cause 
settlement problems [8]. When the expansion joints are placed on the top of a sleeper slab, there is a possibility of cracking and crushing of the approach slab concrete due to the expansion joints and dragging of the approach slab [9]. Seo et al. [10] proposed that the width of the sleeper slab should be at least $5 \mathrm{ft}$.

Dupont and Allen [7] (2002) summarized that excessive settlement can occur merely because the design and/or construction issues were not properly addressed. Issues, such as type of bridge abutment used, joint selection, method of compaction, or under-designed approach slabs are just a few reasons for excessive settlement. The bridge and the abutments are usually constructed prior to the final compaction of the approach pavement, creating a difficult situation for compaction equipment to reach near enough to the bridge end. This causes inadequate compaction in the embankment backfill. If the bridge is highly skewed, the situation becomes worse and large compaction equipment cannot operate near the abutment. Insufficient compaction near the abutment is a major contributor to approach distress. Dupont and Allen [7] also noted that the cost of contributor to approach distress. Dupont and Allen [7] also noted that the cost of any improved design methods must not exceed the life-cycle maintenance cost of existing practices. 


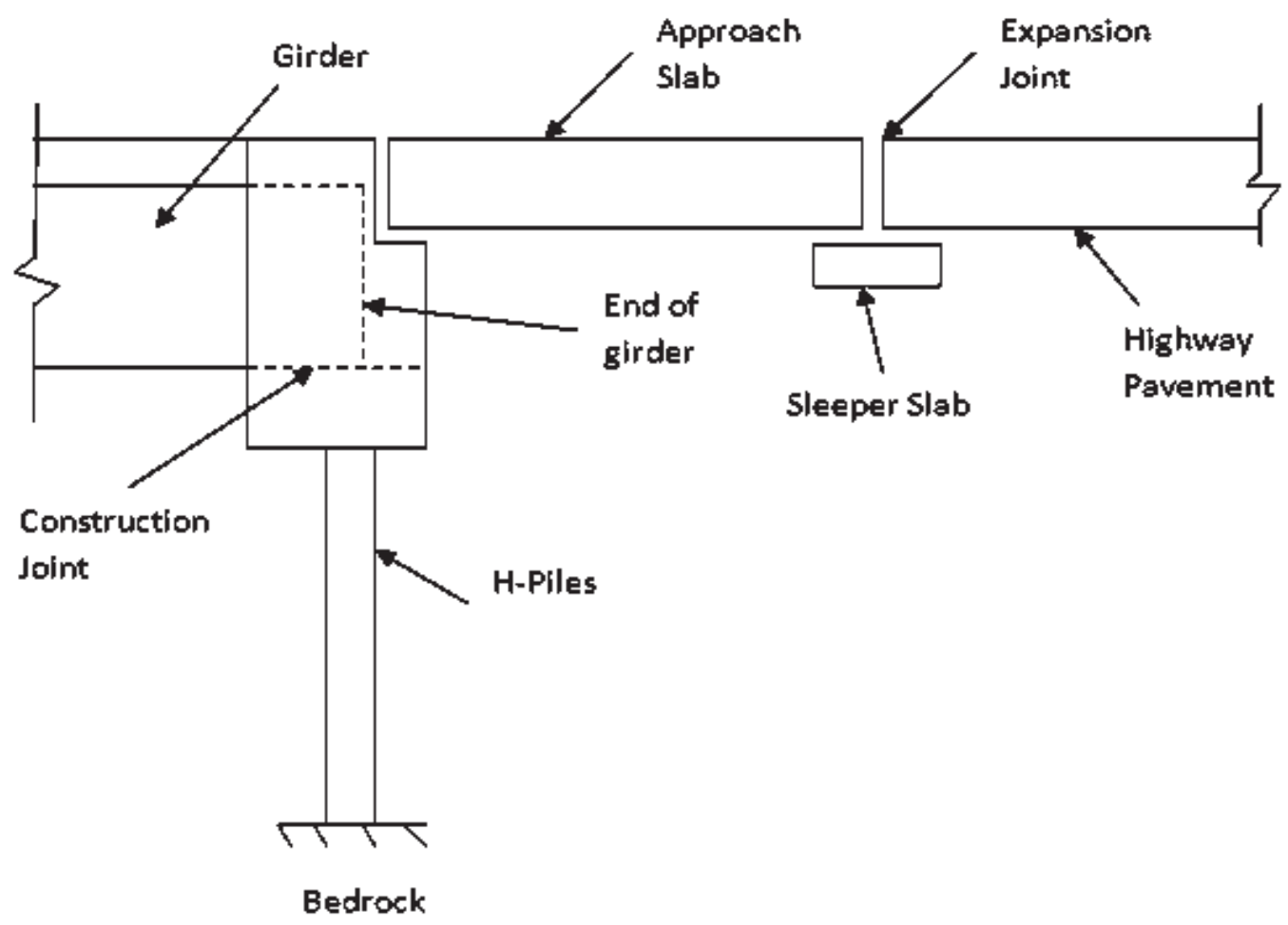

Figure 2.1 - Schematic of an Integral Abutment System with Sleeper Slab [10].

Some studies have focused primarily on s tructural aspects of the approach slab. For example, Cai et al. [11] identified the internal stresses in flat and ribbed approach slabs using a 3 -D finite element model. The recommendations were: major reinforcement of \#7@6" for flat approach slab of $20 \mathrm{ft}$ span length, major reinforcement for flat approach slab of $40 \mathrm{ft}$ to $60 \mathrm{ft}$ span length and major reinforcement for ribbed approach slab of $60 \mathrm{ft}$ to $80 \mathrm{ft}$ span length, as shown in Tables A1 and A2, respectively, in Appendix A. Future recommendations for considering both structural and geotechnical research were also explained as settlement is caused by the weight of the rigid slab and the vehicular load, or a combination thereof. 
Many of the previous studies of bridge approach bumps deal with geotechnical factors that contribute to the problem. According to Stark et al. [1], differential settlement is considered to be the predominant cause of approach distress because of the settlement of the embankment backfill near the end bent. The difference in elevation at pavement-bridge interface contributes to bridge bumps that result in increased vehicle damage and a higher pavement maintenance cost. It also causes a possible danger for motorists.

Briaud et al. [3] investigated the causes of approach slab settlement and listed various problems that can lead to the formation of bumps, as shown in Fig. 2.2. According to this research, it is important to calculate both the short-term and long-term settlement for the structure. Settlement depends primarily on the type of soil. Rock, gravel and sand deposits show short-term settlement as soon as the load is applied. On the other hand, clay and silts are more likely to have long-term settlement problems. It is advisable to use granular fill materials as they are easy to compact. The compaction process and the quality of compaction vary depending on the type of abutment. The authors cited other factors that affect the performance of the bridge approach, including bridge-end conditions, construction methods, roadway paving and the bridge/roadway joint. 


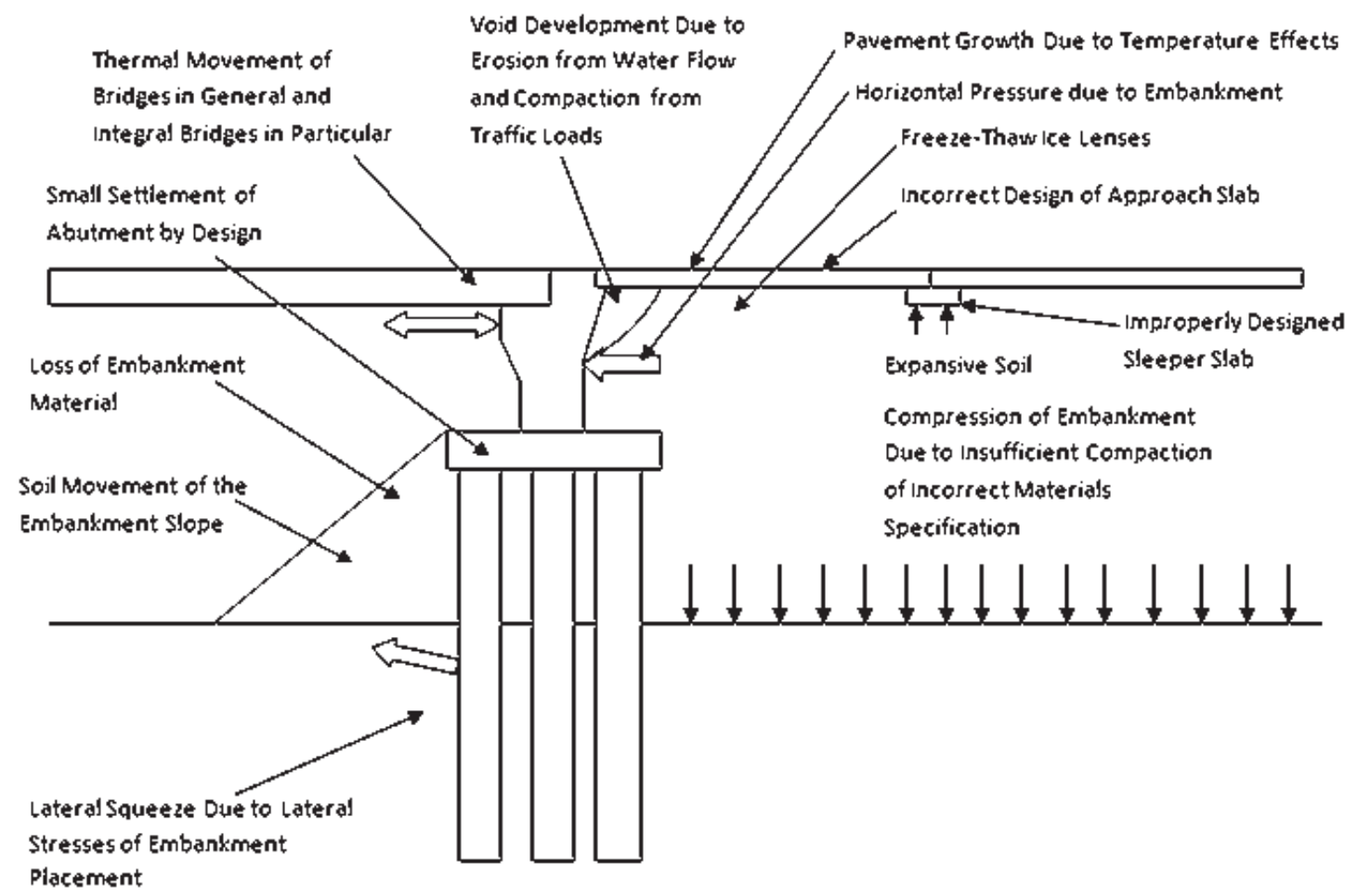

Figure 2.2 - Various factors that can result in formation of bumps [3].

To minimize soil settlement, any bridge construction project should include foundation soil analyses prior to the design and construction of the approach embankment [2]. Previous studies have revealed that stresses applied to the foundation sub-grades come first and foremost from the embankment loading rather than the bridge or traffic loads. Geotechnical studies must be conducted to assess the compression and consolidation potential, in order to better estimate the predictable post-construction settlements [7]. It is also important to study potential shear failures in the foundation that cause lateral deformations and exterior settlement problems. This type of failure is more likely to appear in peat and organic materials. 
Keeping water away from the soil is very important in preventing settlement of soil. A good drainage system should be incorporated with the construction costs. The cost of a drainage system is low when compared to the maintenance costs that might be needed throughout the life of the bridge with poor drainage systems [7].

Ineffective drainage and erosion control methods are additional problems often related to the settlements near bridge abutments [9]. Underlying fill materials that are allowed to become wet from water collected on the bridge pavement due to ineffective seals can flow and er ode underlying backfill materials. This erosion can create voids under approach slabs, producing settlement of approach slabs. Therefore, the design of bridge approaches must be incorporated with a well-organized drainage system. This could also include drainage inlets at the end of the bridge deck so that surface water could be redirected before it reaches the approach slab [9]. The presence of voids under the approach slab can lead to cracking, sinking, instability, and pounding problems [9]. Pressure grouting is used to fill voids under the approach slab with the injection of flowable grout, without having to raise the slab [9].

Foundation soil and embankment play very significant roles in the formation of bumps. Foundation soil should be properly compacted, which becomes difficult at or near the end of bridges, as explained earlier. Thus, the soil is loose and within a few years of approach slab, a void may develop (Figure 2.2) due to erosion and/or compaction [12]. As soil provides structural support for 
the approach slab, the movement of soil reduces the capacity of the approach slab to withstand vehicle loading and can result in the formation of bumps.

Settlement of the soil embankment is one of the major causes of bridge bumps. Hopkins [13] summarized this settlement into three categories: initial, primary and s econdary settlement. Primary and s econdary settlements of embankment soils contribute most to the formation of bumps at pavement-bridge interface. In addition, more settlement is expected for higher embankments as a result of more compression within the embankment and higher loads [14]. Improper drainage of water coming from the bridge and/or approach slab worsens the situation by piping of fines, which facilitates settlement by undermining support for approach slabs and abutments.

Some researchers have proposed innovative methods to control bump formation. According to Wahls [2], bridge abutments can be improved by installing compressible elastic materials between the abutment and the backfill. This material should have elastic properties that permit large recoverable cyclic movement and hydraulic properties that would allow adequate drainage without causing erosion from the backfill. Surface or internal drainage that keeps water off of the slopes was suggested for correcting the superficial erosion of embankments [2]. This can reduce horizontal pressure on the abutment due to the embankment, thereby minimizing relative movement of the abutment and approach slab.

The previous research indicates that settlement of the approach slab can be caused by both structural and geotechnical reasons. Thus in order to reduce 
the formation of bumps, an approach that considers both aspects of design and construction is necessary. The approach slab should be designed to withstand the expected vehicle loads, while the properties and preparation of soil underneath it should be sufficient to provide structural support without settlement. 


\section{CHAPTER 3}

\section{GEOTECHNICAL INVESTIGATIONS USING FIELD DATA}

\subsection{Methods}

Soil is one of the important factors that should be considered in determining and preventing, differential settlement of the pavement/bridge interface. The total loads on the approach slab are all ultimately transferred to the soil. Therefore, soil should be strong enough to bear all the loads without significant erosion or consolidation; otherwise, it will lead to the formation of bumps.

Soils are classified by their particle size, namely gravel, sand, silt and clay. They have different properties and behave differently under loads. The American Association of State Highway Transportation Officials (AASHTO) Soil Classification system is commonly used by the transportation industry. Soil classification requires a sieve analysis for particle size distribution, as well as measurement of liquid limit (LL) and plastic limit (PL) on soil samples. Plastic limit is the moisture content of the soil sample at a transition from semisolid state to plastic state and liquid limit is from plastic state to liquid state.

Several bridges in Columbiana County, Ohio, were visited, and surface soil samples were collected with a trowel. Four bridges had significant bumps and one bridge did not. The soil samples were tested for the purpose of AASHTO classification. The various tests performed on the collected soil samples were 
Sieve Analysis, Liquid Limit (LL) and Plastic Limit (PL). The tests were performed in the Geotechnical Lab at Youngstown State University (YSU). Procedures for

these tests were taken from the YSU Laboratory Manual for Geotechnical Lab (CEEN 4881L). The United States Army Corps of Engineers (USACE) at the Waterways Experiment Station in Vicksburg, Mississippi, proposed an empirical equation for the calculation of liquid limit. All the calculations for liquid limit were performed using Eq. 1, which is given below:

$L L=w(N / 25)^{0.12}$

Where, $\mathrm{N}=$ number of drops of the cup required to close the groove at the moisture content, $\mathrm{w}$.

\subsection{Summary of Results}

Table 3.1 summarizes the results obtained from laboratory experiments on soil samples collected from the five bridge sites. Detailed results are presented in Section 3.3, along with photos of the field sites (calculations are shown in Appendix B). AASHTO classification from A-1-b to A-3, which are very good as subgrade material in pavement construction, shows decreasing granular content in soil, in that order. The results show that the soils from all locations are granular. Grain-size distributions of different sites were studied carefully and compared with the amount of bump present at each bridge site. It was found that the size of bump is greater when percentage of silt and clay in the soil is higher. The highest silt and clay percentage was at Bridge No. COL 30 2667. The bump 
at this bridge was not as severe as some others ( $\mathrm{COL} 30112 \mathrm{~L}$ was the worst); however, as shown in Figure 3.2, an attempt was made to repair the bump at COL 302667.

Table 3.1 - Results obtained on soil samples collected from five bridges in Columbiana County, $\mathrm{OH}$.

\begin{tabular}{|c|c|c|c|c|c|}
\hline Results on & $\begin{array}{c}\text { Bridges without } \\
\text { significant bumps }\end{array}$ & \multicolumn{5}{|c|}{ Bridges with significant bumps } \\
\cline { 2 - 6 } & COL 30 2578 & $\begin{array}{c}\text { COL 30 } \\
2667\end{array}$ & $\begin{array}{c}\text { COL 30 } \\
112 \mathrm{~L}\end{array}$ & $\begin{array}{c}\text { COL 30 } \\
2670\end{array}$ & $\begin{array}{c}\text { COL } 30 \\
3182\end{array}$ \\
\hline Liquid Limit & 34.1 & 21.5 & 24.9 & 33.6 & 32.2 \\
\hline Plastic Limit & 24.5 & 25.5 & 21.9 & 30.7 & 38.4 \\
\hline $\begin{array}{c}\text { Plasticity } \\
\text { Index }\end{array}$ & 9.6 & NP & 3.4 & 2.9 & NP \\
\hline $\begin{array}{c}\text { Soil } \\
\text { Classification }\end{array}$ & A-2-4 (0) & A-3 (0) & A-1-b (0) & A-1-b (0) & A-3 (0) \\
\hline $\begin{array}{c}\text { Silt and Clay } \\
\text { percentage }\end{array}$ & 1.25 & 13.69 & 9.23 & 4.846 & 6.75 \\
\hline
\end{tabular}

Note: Soil samples were collected from the surface i.e. top layer; NP = Non-plastic

Compaction of soil increases the stability of overlying structures and decreases settlement. Soil grain-size distribution, especially the quantity of clay minerals present, is an important factor that affects the compaction. A few years after the construction of pavement, it is usually seen that the soil close to the end bent is lost, creating a void. The most important factors causing this problem are improper compaction of soil and drainage from the bridge. In the compaction process, water is added to the soil and compaction equipment is used to compact the soil properly. The quantity of water added to the soil is kept close to the optimum moisture content during compaction. 
Depending on the type of soil, different ground improvement methods can be used to improve the stability of soil. The different ground improvement techniques that can be used, in new bridges, for granular soil are excavation and replacement, surcharge preloading, dynamic compaction, soil reinforcement, compaction piles, grouting and gravel columns [6], as shown in Table 3.2. Ground improvement techniques often take a lot of time, which results in an increase in construction costs. Therefore many times, two or more ground improvement techniques are combined on a particular site to reduce construction costs. Most of these methods may not be suitable at bridge end bents as it might endanger the bridge structural integrity. Therefore, a thorough geotechnical study has to be conducted before adopting any of these methods.

Table 3.2 - Ground improvement methods based on soil type [6]

\begin{tabular}{|c|c|c|}
\hline Technique & $\begin{array}{c}\text { Cohesionless } \\
\text { Soil }\end{array}$ & Cohesive Soil \\
\hline $\begin{array}{c}\text { Excavation and } \\
\text { Replacement }\end{array}$ & $\mathrm{N}$ & $\mathrm{Y}$ \\
\hline $\begin{array}{c}\text { Preloading w or w/o } \\
\text { Surcharge }\end{array}$ & $\mathrm{Y}$ & $\mathrm{Y}$ \\
\hline $\begin{array}{c}\text { Dynamic } \\
\text { Compaction }\end{array}$ & $\mathrm{Y}$ & $\mathrm{Y}$ \\
\hline Grouting & $\mathrm{Y}$ & $\mathrm{Y}$ \\
\hline Wick Drains & $\mathrm{N}$ & $\mathrm{Y}$ \\
\hline Compaction Piles & $\mathrm{Y}$ & $\mathrm{N}$ \\
\hline Gravel Columns & $\mathrm{Y}$ & $\mathrm{N}$ \\
\hline Lime Treatment & $\mathrm{N}$ & $\mathrm{Y}$ \\
\hline Stone Columns & $\mathrm{N}$ & $\mathrm{Y}$ \\
\hline Soil Reinforcement & $\mathrm{Y}$ & $\mathrm{Y}$ \\
\hline Geopier & $\mathrm{Y}$ & $\mathrm{Y}$ \\
\hline
\end{tabular}


Compaction may be performed on sites to improve the strength and bearing capacity of soil. It not only reduces settlement but also increases stability of slopes. Some of the techniques which may be used in the field for compacting soil are smooth-wheeled rollers, sheepsfoot rollers, rubber-tired rollers vibratory rollers [15]. Vibrations have to be kept as low as possible near the end bent as it can affect the structural integrity of bridges.

\subsection{Detailed Laboratory Data and Photos}

Tables 3.3 to 3.17 show the detailed test results of sieve analysis, plastic limit and liquid limit tests performed on soil samples collected from different bridge sites. Pictures of the bump condition are shown in Figs. 3.1 to 3.5. After comparing lab test results and reviewing the bump pictures of the bridge sites, it was found that the percentage of silt and clay present in the soil has significant effects on bump formation. 
Table 3.3 - Sieve analysis of soil under approach slab of Bridge No. COL 30 2578

\begin{tabular}{|c|c|c|c|c|c|c|c|}
\hline $\begin{array}{c}\text { Sieve } \\
\text { Size }\end{array}$ & $\begin{array}{c}\text { Sieve Wt } \\
(\mathbf{g})\end{array}$ & $\begin{array}{c}\text { Sieve } \\
\mathbf{d i a} \\
(\mathbf{m m})\end{array}$ & $\begin{array}{c}\text { Sieve+Sample } \\
\mathbf{W t}(\mathbf{g})\end{array}$ & $\begin{array}{c}\text { Mass } \\
\text { Retained } \\
\mathbf{( g )}\end{array}$ & $\begin{array}{c}\text { \% } \\
\text { retained }\end{array}$ & Cumulative & \%Finer \\
\hline 1" & 830 & 25.4 & 830 & 0 & 0 & 0 & 100 \\
\hline $3 / 4 "$ & 830 & 19.05 & 830 & 0 & 0 & 0 & 100 \\
\hline $3 / 8 "$ & 542.6 & 9.525 & 559.9 & 17.3 & 3.327 & 3.327 & 96.673 \\
\hline$\# 4$ & 514.5 & 4.75 & 626 & 111.5 & 21.442 & 24.769 & 75.231 \\
\hline$\# 10$ & 484.6 & 2 & 653.2 & 168.6 & 32.423 & 57.192 & 42.808 \\
\hline$\# 40$ & 378.7 & 0.425 & 563.4 & 184.7 & 35.519 & 92.712 & 7.288 \\
\hline$\# 100$ & 328 & 0.15 & 353.3 & 25.3 & 4.865 & 97.577 & 2.423 \\
\hline$\# 200$ & 325 & 0.075 & 331.1 & 6.1 & 1.173 & 98.75 & 1.25 \\
\hline Pan & 500 & & 506.2 & 6.2 & 1.192 & 99.942 & 0.058 \\
\hline
\end{tabular}
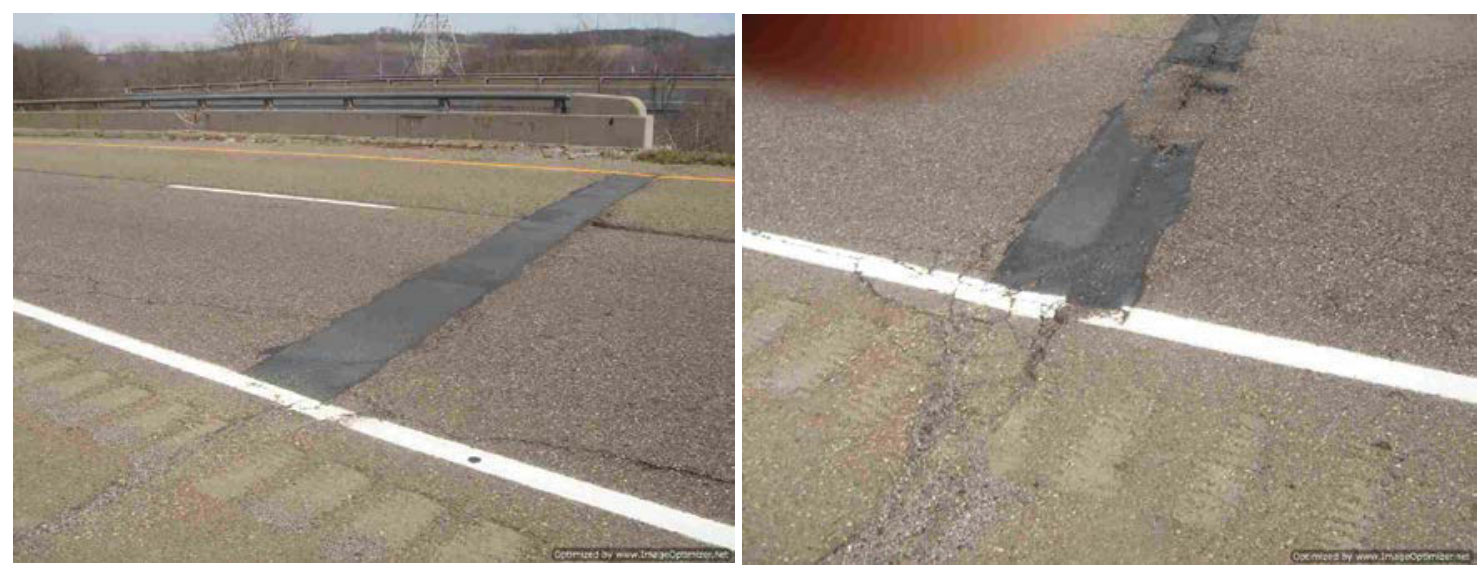

Fig. 3.1 - Pictures of bumps at Bridge No. COL 302578. 
Table 3.4 - Liquid limit test of soil under approach slab of Bridge No. COL 302578

\begin{tabular}{|c|c|}
\hline Number of drops & 24 \\
\hline $\begin{array}{c}\text { Mass of can }+ \\
\text { moist soil }(\mathrm{g})\end{array}$ & 223 \\
\hline $\begin{array}{c}\text { Mass of can }+ \\
\text { dry soil }(\mathrm{g})\end{array}$ & 204.4 \\
\hline Mass of can $(\mathrm{g})$ & 150.1 \\
\hline Mass of water $(\mathrm{g})$ & 18.6 \\
\hline $\begin{array}{c}\text { Mass of dry soil } \\
\text { (g) }\end{array}$ & 54.3 \\
\hline $\begin{array}{c}\text { Moisture content } \\
\text { (\%) }\end{array}$ & 34.3 \\
\hline Liquid limit & 34.1 \\
\hline
\end{tabular}

Table 3.5 - Plastic limit test of soil under approach slab of Bridge No. COL 30 2578

\begin{tabular}{|c|c|c|}
\hline & Sample 1 & Sample 2 \\
\hline $\begin{array}{c}\text { Mass of can + } \\
\text { moist soil (g) }\end{array}$ & 41.3 & 42 \\
\hline $\begin{array}{c}\text { Mass of can + } \\
\text { dry soil (g) }\end{array}$ & 39.5 & 40 \\
\hline Mass of can (g) & 32.1 & 31.9 \\
\hline $\begin{array}{c}\text { Mass of water } \\
\text { (g) }\end{array}$ & 1.8 & 2 \\
\hline $\begin{array}{c}\text { Mass of dry soil } \\
\text { (g) }\end{array}$ & 7.4 & 8.1 \\
\hline $\begin{array}{c}\text { Water content } \\
(\%)\end{array}$ & 24.32 & 24.69 \\
\hline Plastic limit (\%) & & \\
\hline
\end{tabular}


Table 3.6 - Sieve analysis of soil under approach slab of Bridge No. COL 30 2667

\begin{tabular}{|c|c|c|c|c|c|c|c|}
\hline $\begin{array}{c}\text { Sieve } \\
\text { Size }\end{array}$ & $\begin{array}{c}\text { Sieve Wt } \\
(\mathbf{g})\end{array}$ & $\begin{array}{c}\text { Sieve } \\
\text { dia(mm) }\end{array}$ & $\begin{array}{c}\text { Sieve+Sample } \\
\text { Wt (g) }\end{array}$ & $\begin{array}{c}\text { Mass } \\
\text { Retained } \\
(\mathbf{g})\end{array}$ & $\begin{array}{c}\text { \% } \\
\text { retained }\end{array}$ & Cumulative & \%Finer \\
\hline $1 "$ & 830 & 25.4 & 830 & 0 & 0 & 0 & 100 \\
\hline $3 / 4 "$ & 830 & 19.05 & 830 & 0 & 0 & 0 & 100 \\
\hline $3 / 8^{\prime \prime}$ & 531.7 & 9.525 & 543.8 & 12.1 & 2.327 & 2.327 & 97.673 \\
\hline 4 & 505.9 & 4.75 & 530.9 & 25 & 4.808 & 7.135 & 92.865 \\
\hline 10 & 484.6 & 2 & 576.9 & 92.3 & 17.75 & 24.885 & 75.115 \\
\hline 40 & 378.7 & 0.425 & 542.5 & 163.8 & 31.5 & 56.385 & 43.615 \\
\hline 100 & 328 & 0.15 & 452.6 & 124.6 & 23.962 & 80.346 & 19.654 \\
\hline 200 & 325 & 0.075 & 356 & 31 & 5.962 & 86.308 & 13.692 \\
\hline Pan & 499.6 & & 527.2 & 27.6 & 5.308 & 91.615 & 8.385 \\
\hline
\end{tabular}
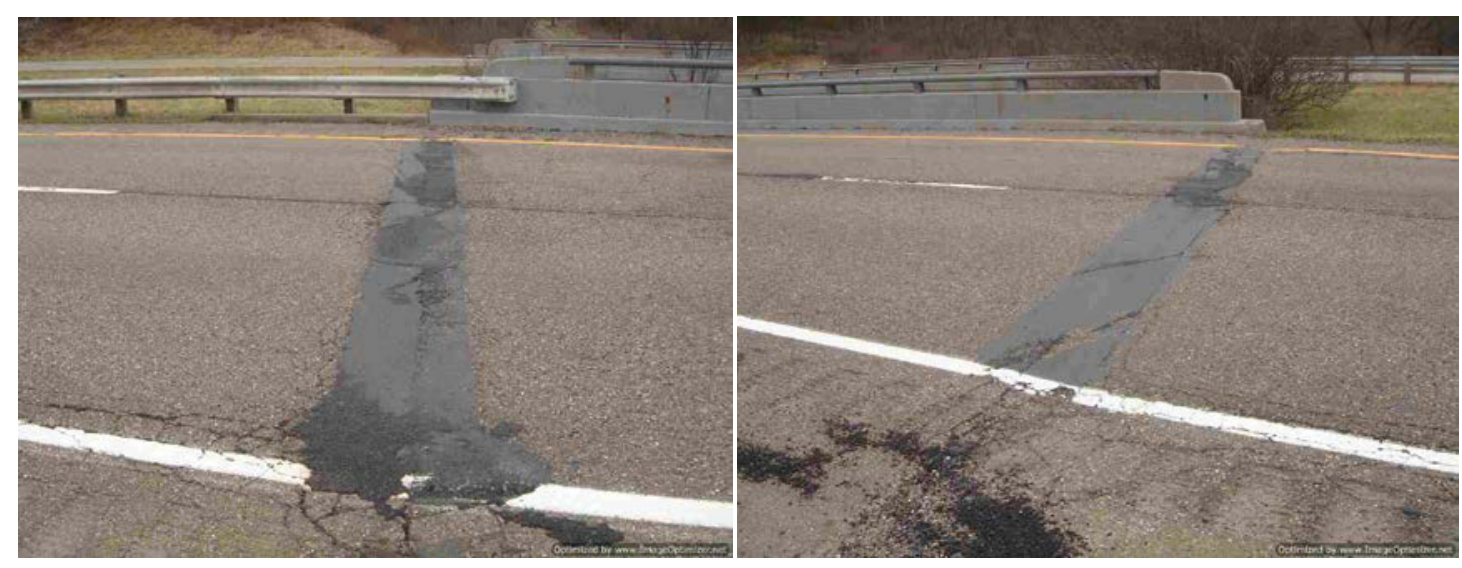

Fig. 3.2 - Pictures of bumps at Bridge No. COL 302667.

Table 3.7 - Liquid limit test of soil under approach slab of Bridge No. COL 30 2667

\begin{tabular}{|c|c|}
\hline Number of drops & 23 \\
\hline $\begin{array}{c}\text { Mass of can + moist } \\
\text { soil }(\mathrm{g})\end{array}$ & 95 \\
\hline $\begin{array}{c}\text { Mass of can + dry } \\
\text { soil }(\mathrm{g})\end{array}$ & 83.7 \\
\hline Mass of can $(\mathrm{g})$ & 31.7 \\
\hline Mass of water $(\mathrm{g})$ & 11.3 \\
\hline Mass of dry soil $(\mathrm{g})$ & 52 \\
\hline $\begin{array}{c}\text { Moisture content } \\
\text { (\%) }\end{array}$ & 21.7 \\
\hline Liquid limit & 21.5 \\
\hline
\end{tabular}


Table 3.8 - Plastic limit test of soil under approach slab of Bridge No. COL 30 2667

\begin{tabular}{|c|c|c|}
\hline & Sample 1 & Sample 2 \\
\hline $\begin{array}{c}\text { Mass of can }+ \\
\text { moist soil (g) }\end{array}$ & 41.5 & 42.1 \\
\hline $\begin{array}{c}\text { Mass of can }+ \\
\text { dry soil (g) }\end{array}$ & 39.7 & 40 \\
\hline $\begin{array}{c}\text { Mass of can (g) } \\
\text { Mass of water (g) }\end{array}$ & 32.5 & 31.9 \\
\hline $\begin{array}{c}\text { Mass of dry soil } \\
\text { (g) }\end{array}$ & 1.8 & 2.1 \\
\hline $\begin{array}{r}\text { Water content } \\
\text { (\%) }\end{array}$ & 25 & 25.9 \\
\hline $\begin{array}{r}\text { Plastic limit (\%) } \\
\text { Mas }\end{array}$ & & \\
\hline
\end{tabular}

Table 3.9 - Sieve analysis of soil under approach slab of Bridge No. COL $112 \mathrm{~L}$

\begin{tabular}{|c|c|c|c|c|c|c|c|}
\hline $\begin{array}{c}\text { Sieve } \\
\text { Size }\end{array}$ & $\begin{array}{c}\text { Sieve Wt } \\
(\mathbf{g})\end{array}$ & $\begin{array}{c}\text { Sieve } \\
\text { dia(mm) }\end{array}$ & $\begin{array}{c}\text { Mass } \\
\text { Wt } \mathbf{( g )}\end{array}$ & $\begin{array}{c}\text { Retained } \\
\mathbf{( g )}\end{array}$ & $\begin{array}{c}\text { \% on each } \\
\text { sieve }\end{array}$ & Cumulative & \%Finer \\
\hline $1 "$ & 830 & 25.4 & 830 & 0 & 0 & 0 & 100 \\
\hline $3 / 4 "$ & 830 & 19.05 & 830 & 0 & 0 & 0 & 100 \\
\hline $3 / 8 "$ & 531.7 & 9.525 & 534.8 & 3.1 & 0.596 & 0.596 & 99.404 \\
\hline 4 & 505.9 & 4.75 & 533.1 & 27.2 & 5.231 & 5.827 & 94.173 \\
\hline 10 & 484.6 & 2 & 630.8 & 146.2 & 28.115 & 33.942 & 66.058 \\
\hline 40 & 378.7 & 0.425 & 538.7 & 160 & 30.769 & 64.712 & 35.288 \\
\hline 100 & 328 & 0.15 & 431.7 & 103.7 & 19.942 & 84.654 & 15.346 \\
\hline 200 & 325 & 0.075 & 356.8 & 31.8 & 6.115 & 90.769 & 9.231 \\
\hline Pan & 499.6 & & 526.3 & 26.7 & 5.135 & 95.904 & 4.096 \\
\hline
\end{tabular}



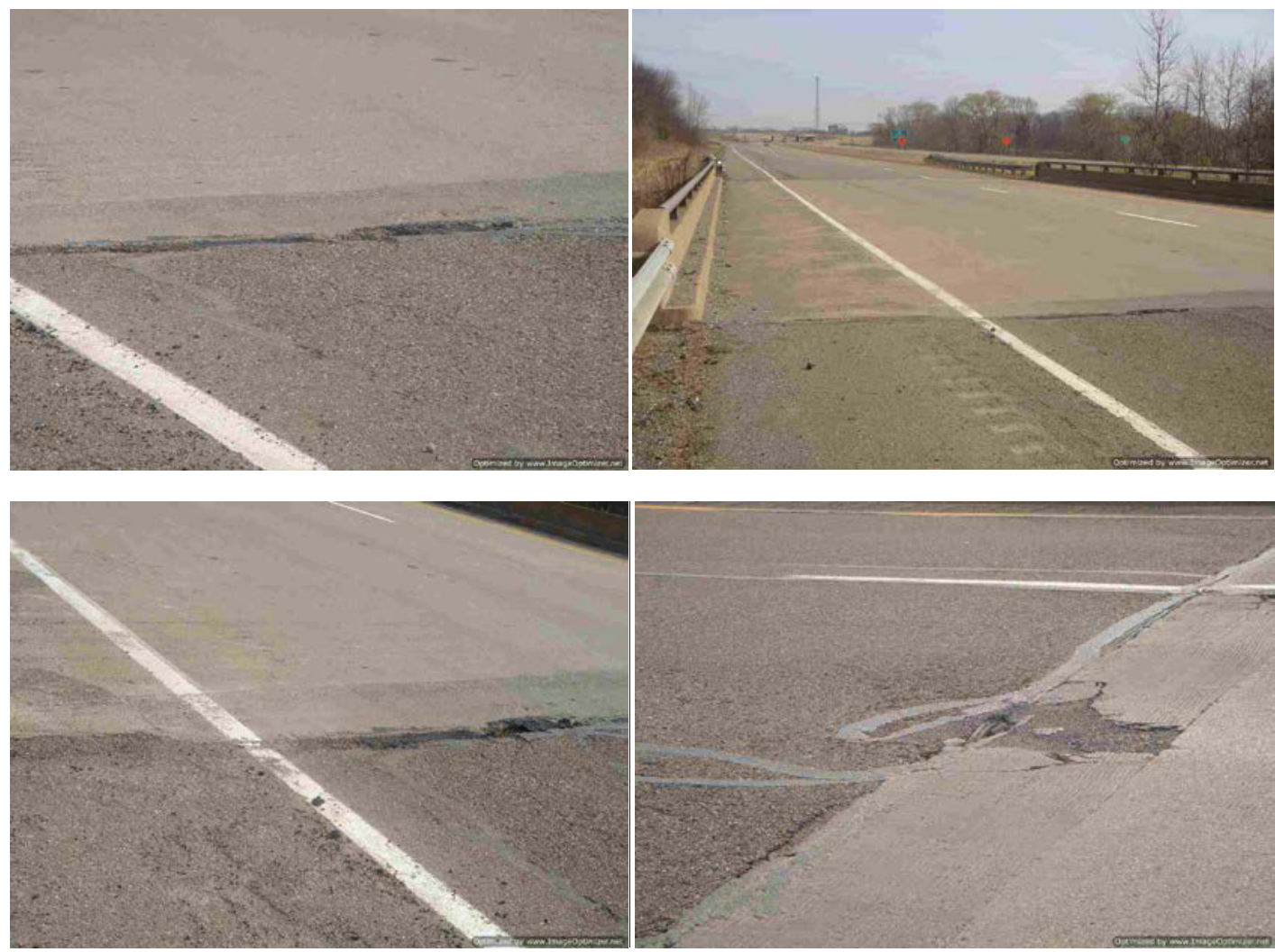

Fig. 3.3 - Pictures of bumps at Bridge No. COL $112 \mathrm{~L}$.

Table 3.10 - Liquid limit test of soil under approach slab of Bridge No. COL 11 $2 \mathrm{~L}$

\begin{tabular}{|c|c|}
\hline $\begin{array}{c}\text { Number of } \\
\text { drops }\end{array}$ & 16 \\
\hline $\begin{array}{c}\text { Mass of can }+ \\
\text { moist soil (g) }\end{array}$ & 64.9 \\
\hline $\begin{array}{c}\text { Mass of can }+ \\
\text { dry soil (g) }\end{array}$ & 58 \\
\hline $\begin{array}{c}\text { Mass of can } \\
\text { (g) }\end{array}$ & 31.8 \\
\hline $\begin{array}{c}\text { Mass of water } \\
\text { (g) }\end{array}$ & 6.9 \\
\hline $\begin{array}{c}\text { Mass of dry } \\
\text { soil (g) }\end{array}$ & 26.2 \\
\hline $\begin{array}{c}\text { Moisture } \\
\text { content (\%) }\end{array}$ & 26.3 \\
\hline Liquid limit & 24.9 \\
\hline
\end{tabular}


Table 3.11 - Plastic limit test of soil under approach slab of Bridge No. COL 11 2L

\begin{tabular}{|c|c|c|}
\hline $\begin{array}{c}\text { Mass of can + } \\
\text { moist soil (g) }\end{array}$ & Sample 1 & Sample 2 \\
\hline $\begin{array}{c}\text { Mass of can + dry } \\
\text { soil (g) }\end{array}$ & 42.3 & 43.4 \\
\hline $\begin{array}{c}\text { Mass of can (g) } \\
\text { Mass of water (g) }\end{array}$ & 32 & 41.4 \\
\hline Mass of dry soil \\
(g)
\end{tabular}

Table 3.12 - Sieve analysis of soil under approach slab of Bridge No. COL 30 2670

\begin{tabular}{|c|c|c|c|c|c|c|c|}
\hline $\begin{array}{c}\text { Sieve } \\
\text { Size }\end{array}$ & $\begin{array}{c}\text { Sieve Wt } \\
(\mathbf{g})\end{array}$ & $\begin{array}{c}\text { Sieve } \\
\text { dia(mm) }\end{array}$ & $\begin{array}{c}\text { Sieve+Sample } \\
\text { Wt } \mathbf{( g )}\end{array}$ & $\begin{array}{c}\text { Mass } \\
\text { Retained } \\
(\mathbf{g})\end{array}$ & $\begin{array}{c}\text { \% on each } \\
\text { sieve }\end{array}$ & Cumulative & \%Finer \\
\hline $1 "$ & 830 & 25.4 & 830 & 0 & 0 & 0 & 100 \\
\hline $3 / 4 "$ & 830 & 19.05 & 830 & 0 & 0 & 0 & 100 \\
\hline $3 / 8 "$ & 542.7 & 9.525 & 549.4 & 6.7 & 1.288 & 1.288 & 98.712 \\
\hline 4 & 514.6 & 4.75 & 586.1 & 71.5 & 13.75 & 15.038 & 84.962 \\
\hline 10 & 484.6 & 2 & 665 & 180.4 & 34.692 & 49.731 & 50.269 \\
\hline 40 & 378.7 & 0.425 & 561 & 182.3 & 35.058 & 84.788 & 15.212 \\
\hline 100 & 328 & 0.15 & 373 & 45 & 8.654 & 93.442 & 6.558 \\
\hline 200 & 325 & 0.075 & 333.9 & 8.9 & 1.712 & 95.154 & 4.846 \\
\hline Pan & 499.6 & & 505.3 & 5.7 & 1.096 & 96.25 & 3.75 \\
\hline
\end{tabular}



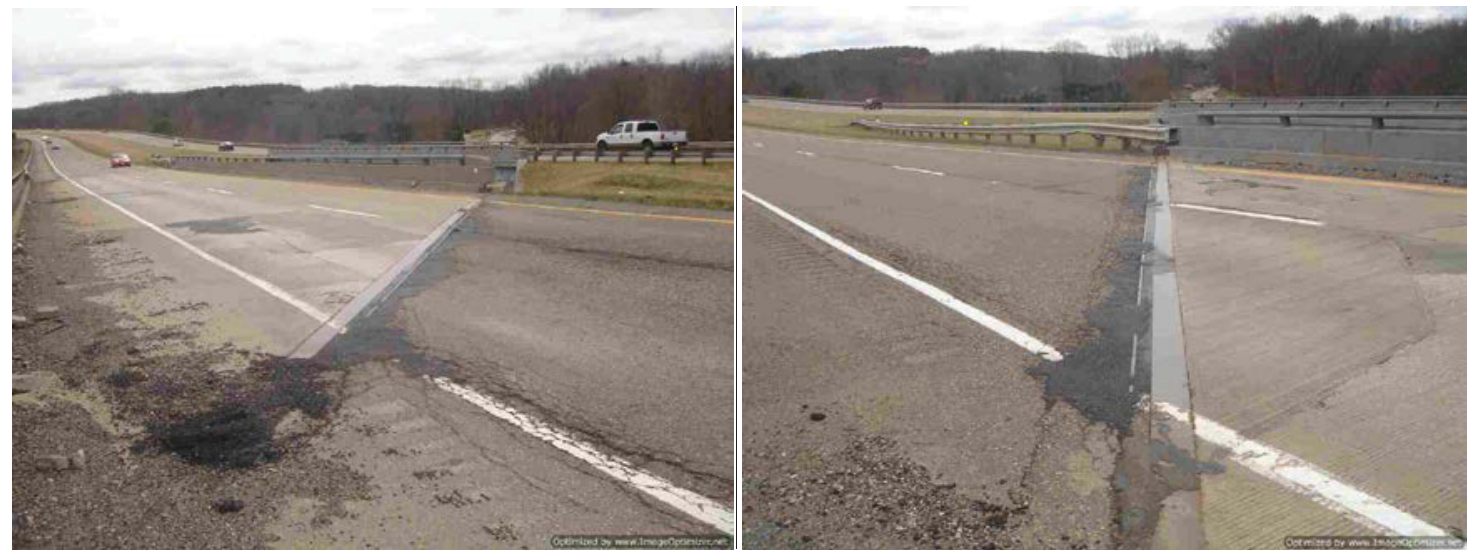

Fig. 3.4 - Pictures of bumps at Bridge No. COL 302670.

Table 3.13 - Liquid limit test of soil under approach slab of Bridge No. COL 30 2670

\begin{tabular}{|c|c|}
\hline Number of drops & 18 \\
\hline $\begin{array}{c}\text { Mass of can }+ \\
\text { moist soil }(\mathrm{g})\end{array}$ & 45.5 \\
\hline $\begin{array}{c}\text { Mass of can + dry } \\
\text { soil }(\mathrm{g})\end{array}$ & 42 \\
\hline Mass of can (g) & 32 \\
\hline Mass of water (g) & 3.5 \\
\hline $\begin{array}{c}\text { Mass of dry soil } \\
(\mathrm{g})\end{array}$ & 10 \\
\hline $\begin{array}{c}\text { Moisture content } \\
(\%)\end{array}$ & 35 \\
\hline Liquid limit & 33.6 \\
\hline
\end{tabular}


Table 3.14 - Plastic limit test of soil under approach slab of Bridge No. COL 30 2670

\begin{tabular}{|c|c|c|}
\hline & Sample 1 & Sample 2 \\
\hline $\begin{array}{c}\text { Mass of can + } \\
\text { moist soil (g) }\end{array}$ & 41.1 & 41 \\
\hline $\begin{array}{c}\text { Mass of can + } \\
\text { dry soil (g) }\end{array}$ & 39 & 38.8 \\
\hline $\begin{array}{c}\text { Mass of can (g) } \\
\text { (g) }\end{array}$ & 32 & 31.8 \\
\hline $\begin{array}{c}\text { Mass of water } \\
\text { (g) }\end{array}$ & 2.1 & 2.2 \\
\hline $\begin{array}{c}\text { Mass of dry soil } \\
\text { (\%) }\end{array}$ & 30 & 31.4 \\
\hline $\begin{array}{c}\text { Water content } \\
\text { Plastic limit (\%) }\end{array}$ & & \\
\hline
\end{tabular}

Table 3.15 - Sieve analysis of soil under approach slab of Bridge No. COL 30 3182

\begin{tabular}{|c|c|c|c|c|c|c|c|}
\hline $\begin{array}{c}\text { Sieve } \\
\text { Size }\end{array}$ & $\begin{array}{c}\text { Sieve Wt } \\
(\mathbf{g})\end{array}$ & $\begin{array}{c}\text { Sieve } \\
\text { dia(mm) }\end{array}$ & $\begin{array}{c}\text { Sieve+Sample } \\
\mathbf{W t}(\mathbf{g})\end{array}$ & $\begin{array}{c}\text { Mass } \\
\text { Retained } \\
\mathbf{( g )}\end{array}$ & $\begin{array}{c}\text { \% on each } \\
\text { sieve }\end{array}$ & Cumulative & \%Finer \\
\hline $1 "$ & 830 & 25.4 & 830 & 0 & 0 & 0 & 100 \\
\hline $3 / 4 "$ & 830 & 19.05 & 830 & 0 & 0 & 0 & 100 \\
\hline $3 / 8 "$ & 542.7 & 9.525 & 552.7 & 10 & 1.923 & 1.923 & 98.077 \\
\hline 4 & 514.6 & 4.75 & 557.7 & 43.1 & 8.288 & 10.212 & 89.788 \\
\hline 10 & 484.6 & 2 & 542.7 & 58.1 & 11.173 & 21.385 & 78.615 \\
\hline 40 & 378.7 & 0.425 & 595.6 & 216.9 & 41.712 & 63.096 & 36.904 \\
\hline 100 & 328 & 0.15 & 452.6 & 124.6 & 23.962 & 87.058 & 12.942 \\
\hline 200 & 325 & 0.075 & 357.2 & 32.2 & 6.192 & 93.25 & 6.75 \\
\hline Pan & 499.6 & & 516.9 & 17.3 & 3.327 & 96.577 & 3.423 \\
\hline
\end{tabular}



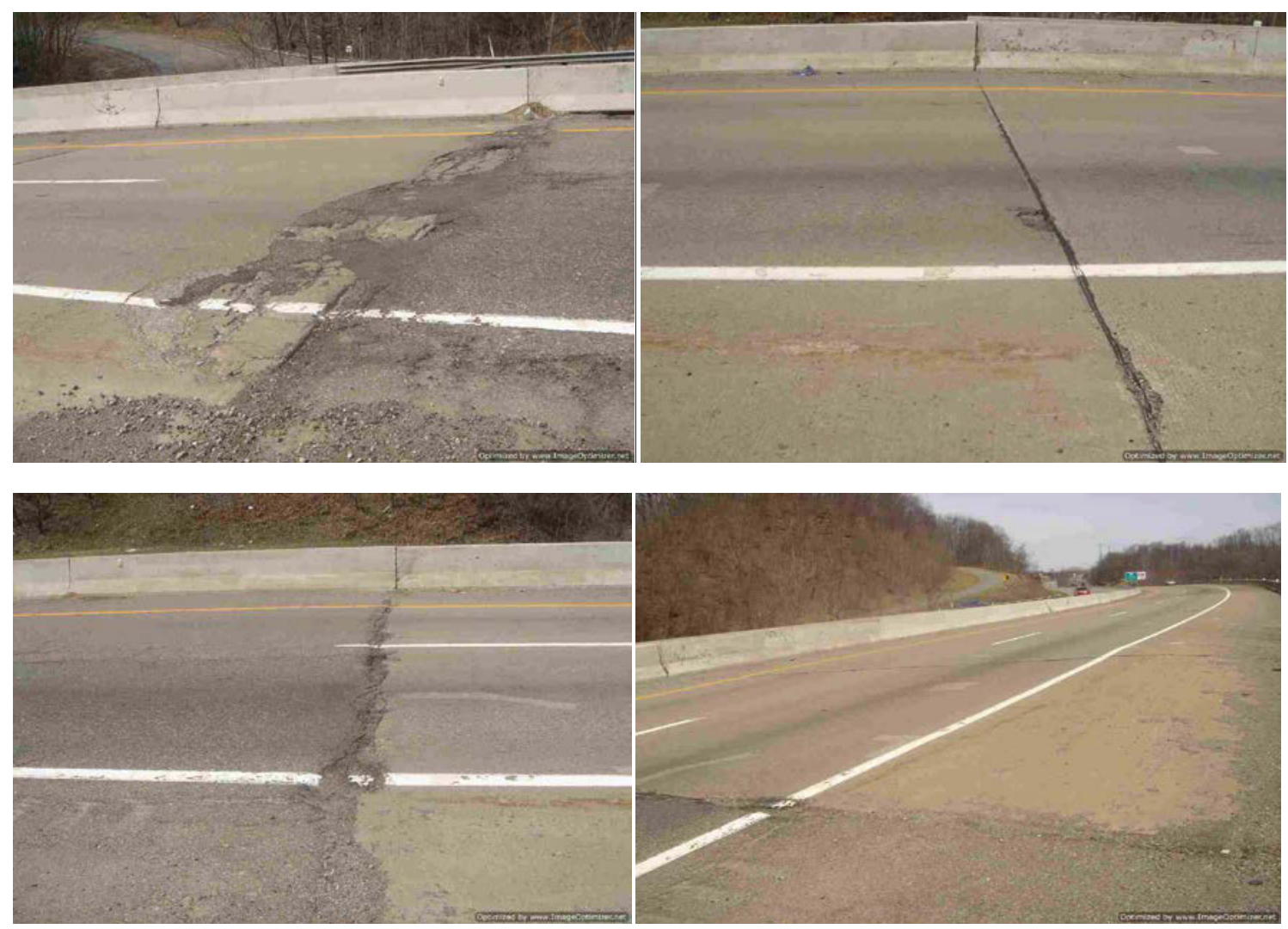

Fig. 3.5 - Pictures of bumps at Bridge No. COL 303182.

Table 3.16 - Liquid limit test of soil under approach slab of Bridge No. COL 30 3182

\begin{tabular}{|c|c|}
\hline Number of drops & 28 \\
\hline $\begin{array}{c}\text { Mass of can }+ \\
\text { moist soil }(\mathrm{g})\end{array}$ & 51.6 \\
\hline $\begin{array}{c}\text { Mass of can }+ \\
\text { dry soil }(\mathrm{g})\end{array}$ & 46.8 \\
\hline Mass of can $(\mathrm{g})$ & 31.7 \\
\hline $\begin{array}{c}\text { Mass of water } \\
(\mathrm{g})\end{array}$ & 4.8 \\
\hline $\begin{array}{c}\text { Mass of dry soil } \\
(\mathrm{g})\end{array}$ & 15.1 \\
\hline $\begin{array}{c}\text { Moisture content } \\
(\%)\end{array}$ & 31.8 \\
\hline Liquid limit & 32.2 \\
\hline
\end{tabular}


Table 3.17 - Plastic limit test of soil under approach slab of Bridge No. COL 30 3182

\begin{tabular}{|c|c|c|}
\hline & Sample 1 & Sample 2 \\
\hline $\begin{array}{c}\text { Mass of can + } \\
\text { moist soil (g) }\end{array}$ & 41.5 & 43 \\
\hline $\begin{array}{c}\text { Mass of can + } \\
\text { dry soil (g) }\end{array}$ & 39.1 & 39.8 \\
\hline Mass of can (g) & 32.4 & 32 \\
\hline $\begin{array}{c}\text { Mass of water } \\
\text { (g) }\end{array}$ & 2.4 & 3.2 \\
\hline $\begin{array}{c}\text { Mass of dry soil } \\
\text { (g) }\end{array}$ & 6.7 & 7.8 \\
\hline $\begin{array}{c}\text { Water content } \\
\text { (\%) }\end{array}$ & 35.8 & 41 \\
\hline Plastic limit (\%) & \multicolumn{2}{|c|}{38.4} \\
\hline
\end{tabular}




\section{CHAPTER 4}

\section{STRUCTURAL ANALYSIS OF APPROACH SLABS}

\subsection{Hand Calculations}

This chapter contains the results of structural investigations of approach slab performance using both hand calculations and finite element method simulations. Approach slab drawings of different state DOTs were obtained and analyzed. Applied moment and internal moment capacity of the approach slabs for these states were calculated and compared. The calculations, shown in Appendix C, were performed considering the approach slab as a simply supported doubly reinforced beam with no soil support underneath it. Truck load was placed in such a way over the beam that it produces maximum applied moment. $L_{\min }$ is the minimum length of the approach slab, $h$ is the thickness of the slab, $f_{c^{\prime}}$ is 28 -day compressive strength of concrete, $A_{s}$ and $A_{s}$ ' are the area of bottom and top reinforcing bars, d' and $\mathrm{C}_{\mathrm{c}}$ are the top and bottom clear cover, and $\Phi M_{n}$ and $M_{u}$ are the moment capacity and applied moment of approach slab. Table 4.1 shows the results of calculations performed on approach slabs of various state DOTs. There is no top reinforcement provided in the design of approach slabs in Kentucky. The length of approach slab varies from $15 \mathrm{ft}$ for Arizona to $30 \mathrm{ft}$ in Ohio. The approach slabs of Arizona, Florida, Indiana and Michigan were found to be strength deficient when all soil support is lost under the approach slab. 
Table 4.1 - Approach slab designs in different state DOTs

\begin{tabular}{|c|c|c|c|c|c|c|c|c|c|}
\hline \multirow[t]{2}{*}{ State } & $\mathrm{L}_{\min }$ & $\mathbf{h}$ & $f_{c^{\prime}}$ & $A_{s}$ & $\mathbf{A}_{\mathbf{s}}$ & $d^{\prime}$ & $\mathrm{C}_{\mathrm{c}}$ & $\Phi M_{n}$ & $\mathbf{M}_{\mathrm{u}}$ \\
\hline & (ft.) & (in.) & (ksi) & $\left(\mathrm{in}^{2} / \mathrm{ft}\right)$ & $\left(\mathrm{in}^{2} / \mathrm{ft}\right)$ & (in.) & (in.) & $(k i p * f t / f t)$ & $(k i p * f t / f t)$ \\
\hline$A Z^{*}$ & 15 & 12 & 3 & 1.053 & 0.133 & 2.5 & 3 & 37.7 & 39.56 \\
\hline $\mathrm{FL}^{*}$ & 30 & 12 & 4.5 & 1.053 & 0.31 & 2.5 & 4 & 31.05 & 96.79 \\
\hline $\mathbb{I N}^{*}$ & 20 & 10 & 4 & 0.63 & 0.203 & 2.5 & 2 & 19.14 & 52.5 \\
\hline $\mathrm{KY}$ & 25 & 17 & 3.5 & 1.58 & 0 & $\mathrm{~N} / \mathrm{A}$ & 3 & 90.1 & 76.61 \\
\hline $\mathrm{Ml}^{*}$ & 20 & 12 & 4.5 & 0.895 & 0.895 & 3 & 3 & 21.87 & 54.06 \\
\hline $\mathrm{OH}$ & 25 & 15 & 4.5 & 2.18 & 0.207 & 3 & 3 & 102.4 & 74.17 \\
\hline PA & 25 & 16 & 3.5 & 1.693 & 0.31 & 2.5 & 3 & 85.22 & 75.39 \\
\hline
\end{tabular}

* denotes that applied moment is more than internal moment capacity; N/A means Not Available

\subsection{Finite Element Analysis}

The approach slab is placed at the end of the bridges with its one end resting on an end bent and the other end on a sleeper slab. Movement of soil beneath the abutment is one of the most predominant causes for the formation of bumps. A parametric study was conducted on the design parameters, such as stresses and deflections. Two separate models were built in Autodesk ALGOR Simulation Professional 2010 [16] finite element analysis software. Model A (Fig. 4.1) had an approach slab with soil underneath, while Model B (Fig. 4.2) had an approach slab without any soil to replicate the situation of an approach slab where the soil underneath is assumed to have eroded or settled. Concrete below the neutral axis was neglected for Model $B$, to replicate a cracked concrete section, and beams with high stiffness were used to transfer loads to bottom reinforcement. The span length was $25 \mathrm{ft}$ and width was $10 \mathrm{ft}$ for both models; these are typical approach slab dimensions in Ohio. The thickness of approach slab was taken as 15 in, a bottom reinforcement of \#10 bars at 6 in on center (to match nodes) and a top reinforcement of $\# 5 \mathrm{~b}$ ars at 18 in on center were 
provided (Fig. 4.3); these values are based on ODOT recommendations. Due to the complexity of the structure, a manual meshing procedure was followed. For approach slab, a mesh of rectangle 6 in length and 3 in width was selected while for the other parts, such as end bent, sleeper slab and soil, a mesh of square 6 in was selected.

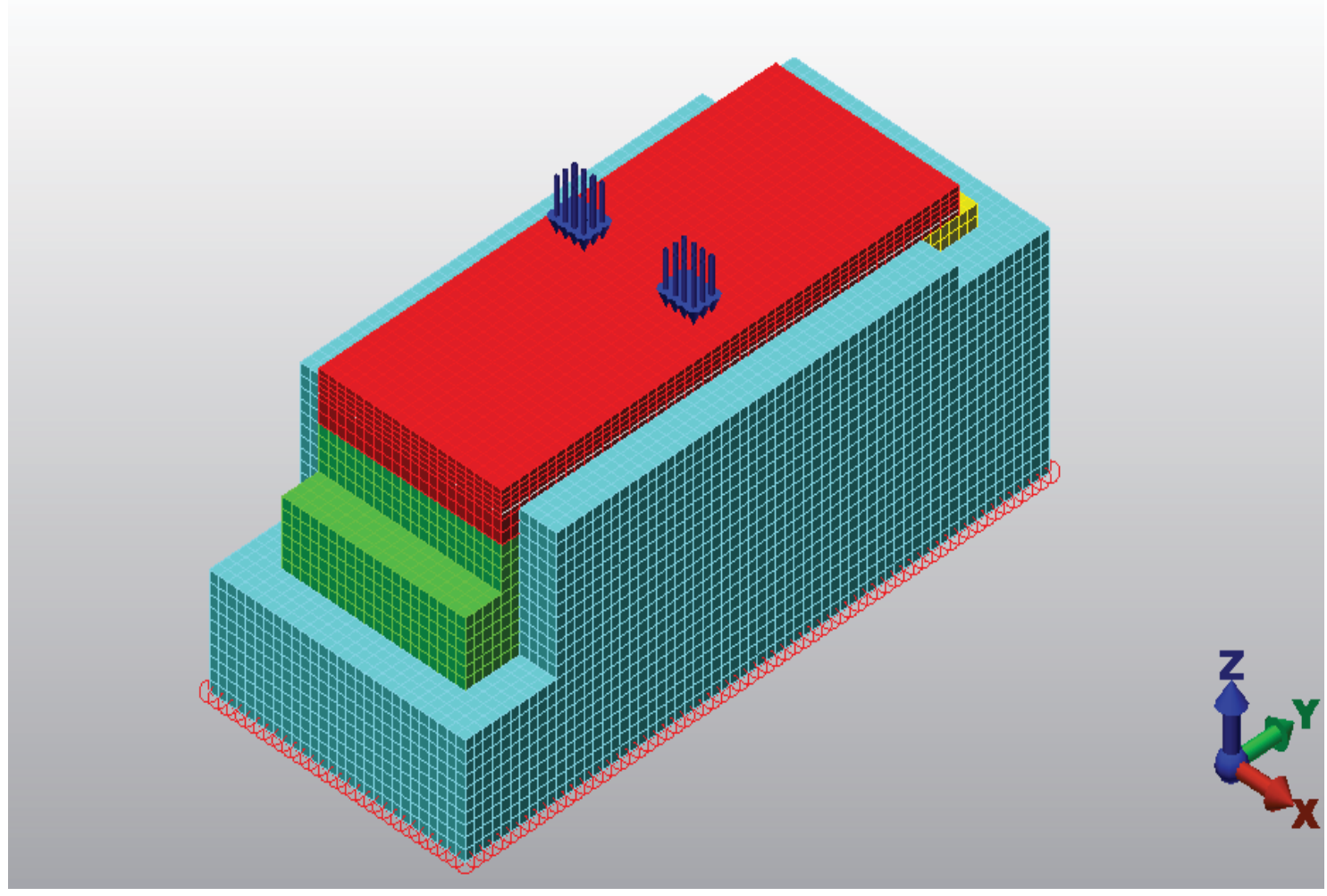

Figure 4.1 - FE Model A of approach slab with soil. 


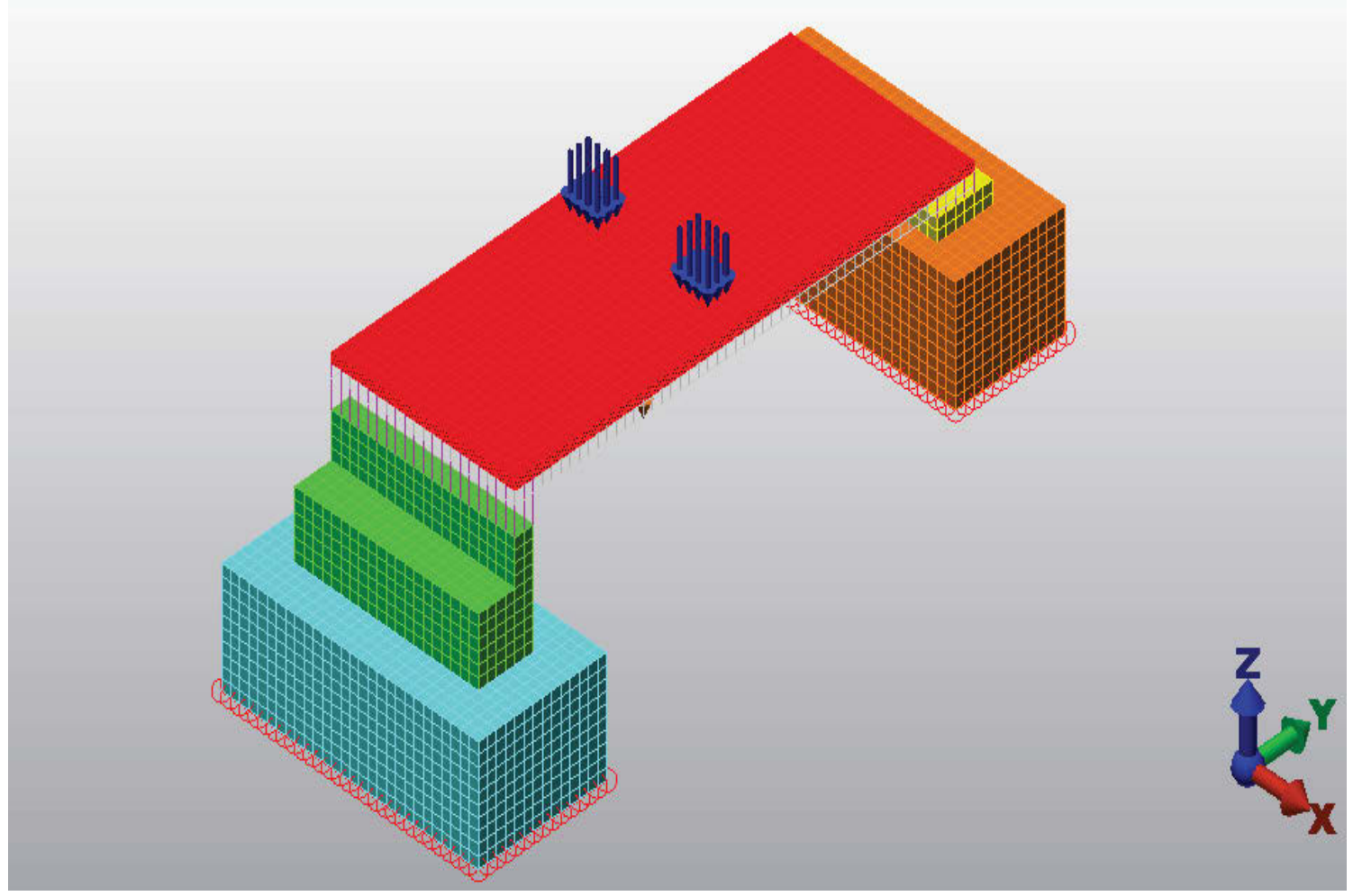

Figure 4.2 - FE Model B of approach slab without soil. 


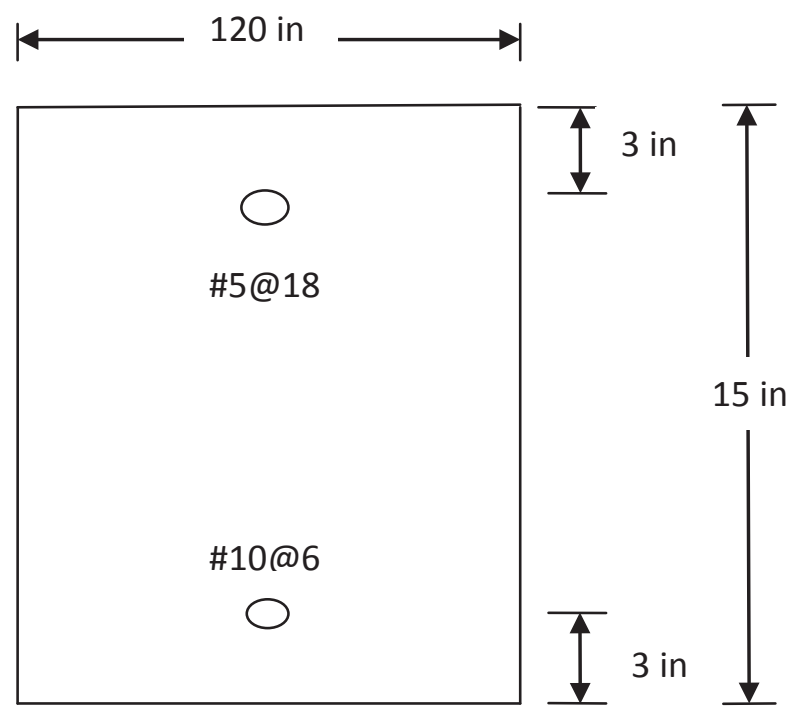

Figure 4.3 - Cross-section of approach slab models.

A static stress with linear material model analysis was performed on Model A and Model B. In static stress with linear material models, static loads, such as forces and moments, are applied on a finite element model. Boundary conditions are applied to the model and material properties are defined. Forces are assumed to be constant for an infinite period of time while resulting strain and deformations are small. A sleeper slab and an end bent were also built on the ends of the approach slab and all three parts were considered to be medium strength concrete (4000 psi to $5000 \mathrm{psi}$ ). Dead load of the whole structure was also considered and an HL-93 single-lane static truck load was placed on the slab in such a way that it produces maximum deflection and moment on the slab. A HL-93 truck consists of three axle loads of 8 kip, 32 kip and 32 kip, respectively, and each axle is at a center distance of $14 \mathrm{ft}$. The lateral distance 
between tires is $6 \mathrm{ft}$. According to AASHTO Bridge Design Specifications [17], the tire contact area of the wheel consisting of one or two tires shall be assumed to be a single rectangle, whose width is $20 \mathrm{in}$. and length is $10 \mathrm{in}$. But due to the complexity of meshes in the model, the tire contact area was taken as $12 \mathrm{in.}$ in length and $18 \mathrm{in}$. in width. The soil properties were user defined at the values shown in Table 4.2.

Table 4.2 - Properties of soil for FE model

\begin{tabular}{|c|c|c|c|c|c|}
\hline & $\begin{array}{l}\text { Mass Density } \\
\left(\mathrm{lbf}^{*} \mathrm{~s}^{2} / \mathrm{in} / \mathrm{in}^{3}\right)\end{array}$ & $\begin{array}{c}\text { Modulus of } \\
\text { Elasticity } \\
\left(\mid \mathrm{bf} / \mathrm{in}^{2}\right)\end{array}$ & $\begin{array}{l}\text { Poisson's } \\
\text { Ratio }\end{array}$ & $\begin{array}{c}\text { Thermal } \\
\text { Coefficient of } \\
\text { Expansion }\left(1 /^{0}\right)\end{array}$ & $\begin{array}{c}\text { Shear Modulus } \\
\text { of Elasticity } \\
\left({\left.\mathrm{Ibf} / \mathrm{in}^{2}\right)}^{2}\right.\end{array}$ \\
\hline $\begin{array}{c}\text { Soil } \\
\text { Properties }\end{array}$ & 0.000165 & 6500 & 0.25 & 0.00006 & 2610.7 \\
\hline
\end{tabular}

The contact between the end bent and approach slab was taken as bonded because the top reinforcement runs from approach slab to end bent. The two surfaces are in perfect contact throughout the analysis when bonded, and the loads are transmitted from one part to the adjacent part. In a stress analysis, when a node on o ne surface deflects, the node on the adjoining surface will deflect by the same amount in the same direction.

In ALGOR, a surface contact between two structural components is created when the gap between the parts is zero. The nodes are free to move 
away from one another, but they cannot pass through each other when they come into contact. The approach slab was placed over the sleeper slab with surface contact considered between them; a coefficient of static friction of 0.75 was specified. The contact between concrete parts and soil were also taken as surface-to-surface contact with a value of 0.3 for coefficient of static friction.

The boundary conditions were taken as pinned for soil beneath the structure for both models. Analysis was run in ALGOR for both Model A and Model B, and values for deflections and stresses were compared at various parts of the model. The maximum deflection for Models A and B were 0.19 in and 1.34 in, respectively, as shown in Figs. 4.4A and 4.4B. Deflections increase approximately by seven times when the soil is removed, which may cause cracks in the structure due to fatigue and could eventually cause bumps. The value of maximum tensile stress in concrete in Model A was found to be 403 psi (Fig. $4.5 \mathrm{~A})$, which is less than the tensile strength of concrete $\left(7.5^{*}(4500)^{0.5}=503 \mathrm{psi}\right)$. This shows that the concrete slab should not crack when it has complete soil support under it. When soil support is lost the concrete starts to crack and approach slab starts to take a concave shape. The value of maximum compressive stress in concrete for Model B was 3137 psi (Fig. 4.5B), which is less than compressive strength of concrete (4500 psi), showing that concrete above neutral axis has not cracked even though complete soil support is lost. The value of maximum stress in bottom reinforcement for Model B was 28,062 psi (Fig. 4.5C) which is less than yield strength of steel (60,000 psi). This stress value was used to calculate the maximum applied moment (shown in Appendix 
C), which was found to be $61 \mathrm{kip}-\mathrm{ft} / \mathrm{ft}$. The maximum moment capacity calculated using the ODOT specifications for the same $25 \mathrm{ft}$ long approach slab was 102 kip-ft/ft (shown in Appendix C). Therefore, the present ODOT design for an approach slab of span length $25 \mathrm{ft}$ was found to be sufficient for static HL-93 truck loading.

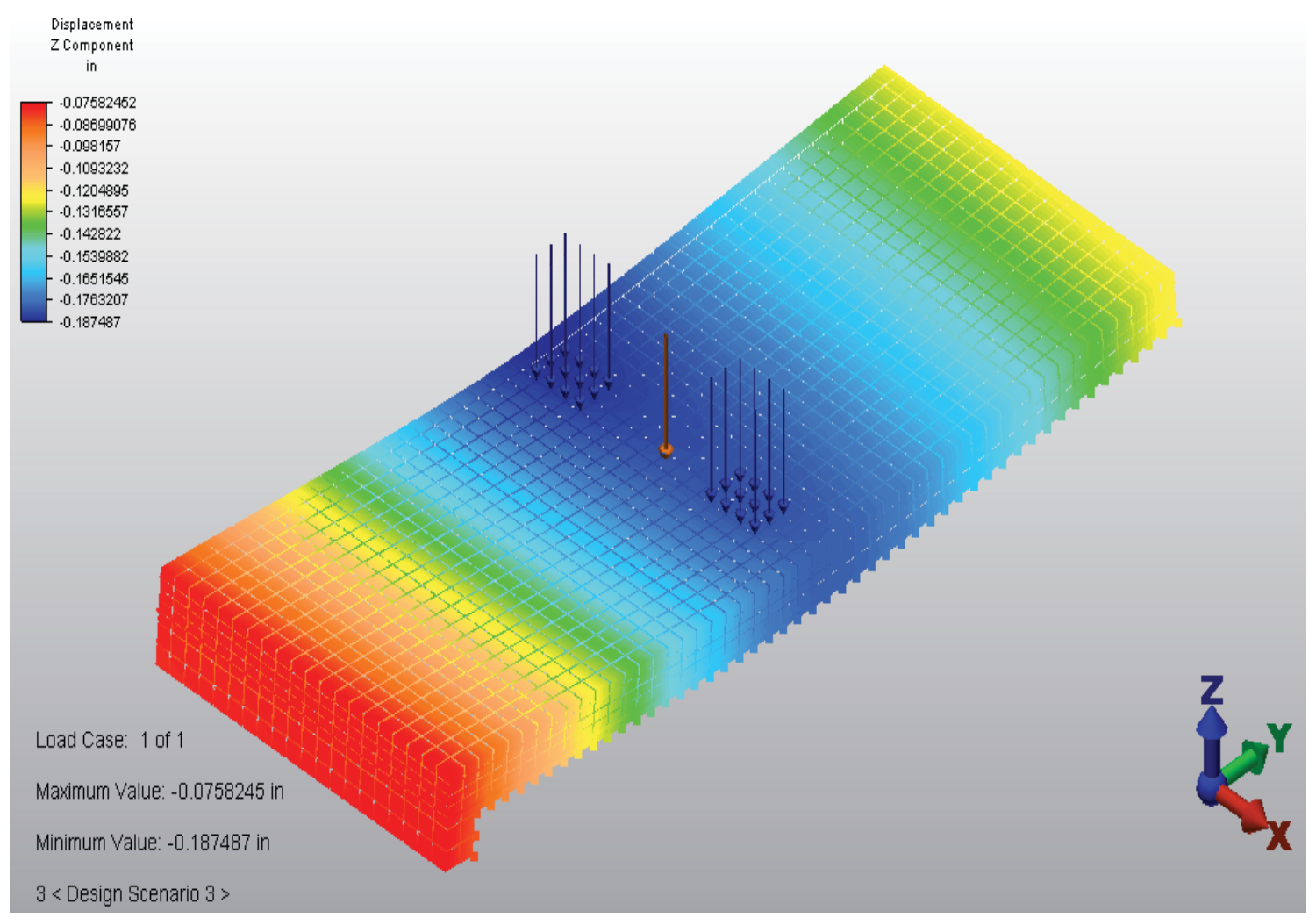

Figure 4.4A - FE Model A showing results of displacement. 


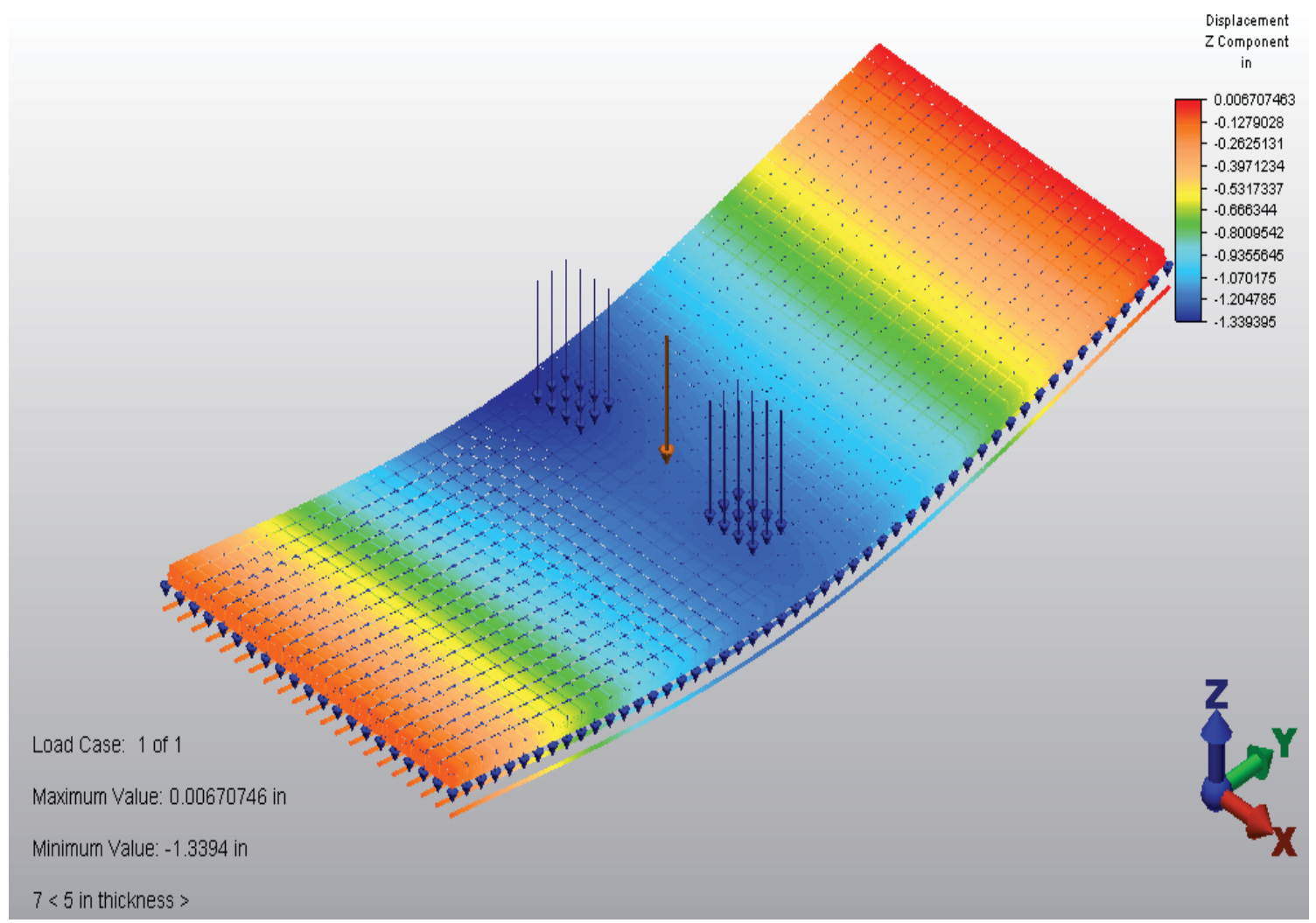

Figure 4.4B - FE Model B showing results of displacement. 


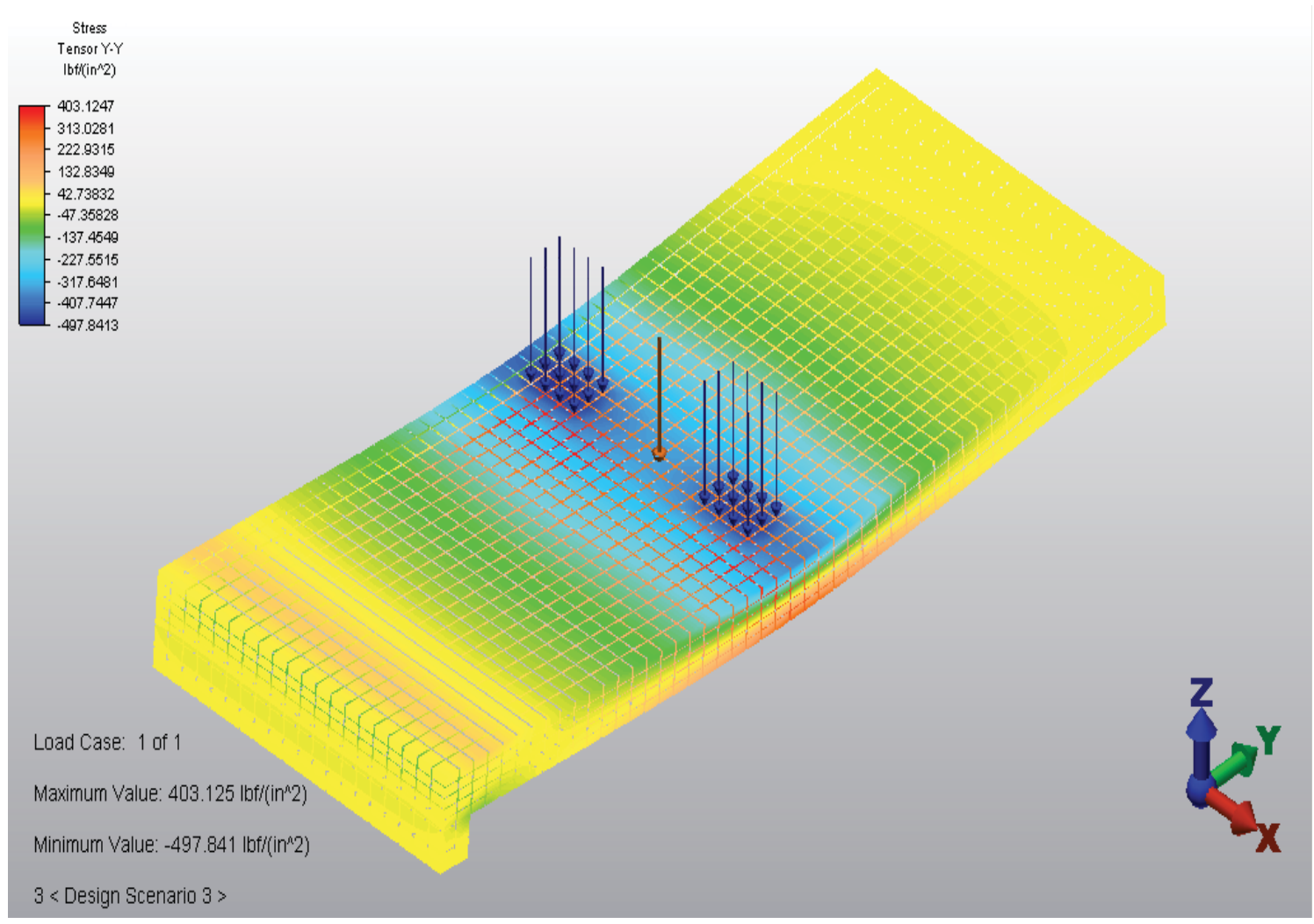

Figure 4.5A - FE Model A showing results of stresses in concrete. 


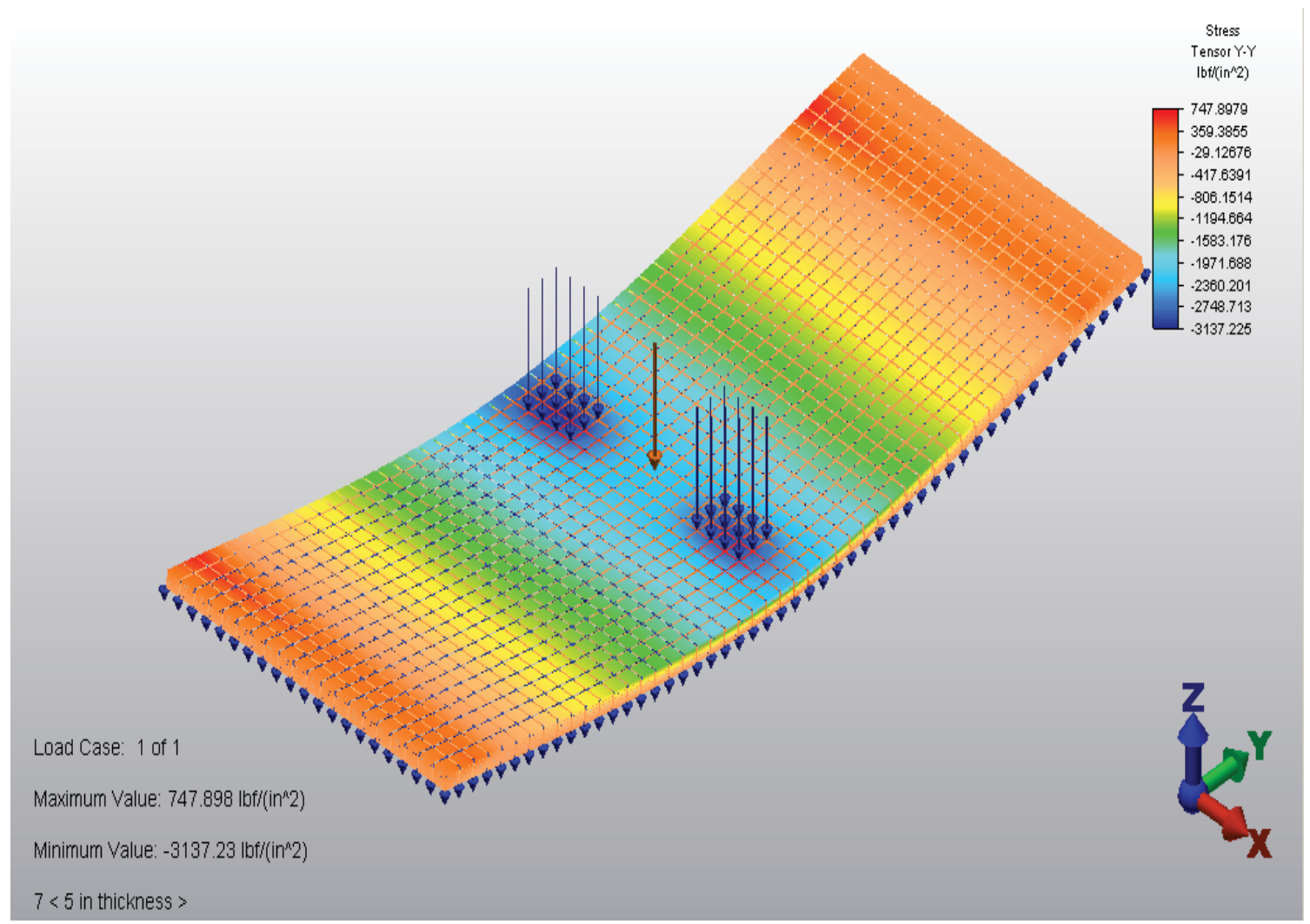

Figure 4.5B - FE Model B showing results of compressive stresses in concrete. 


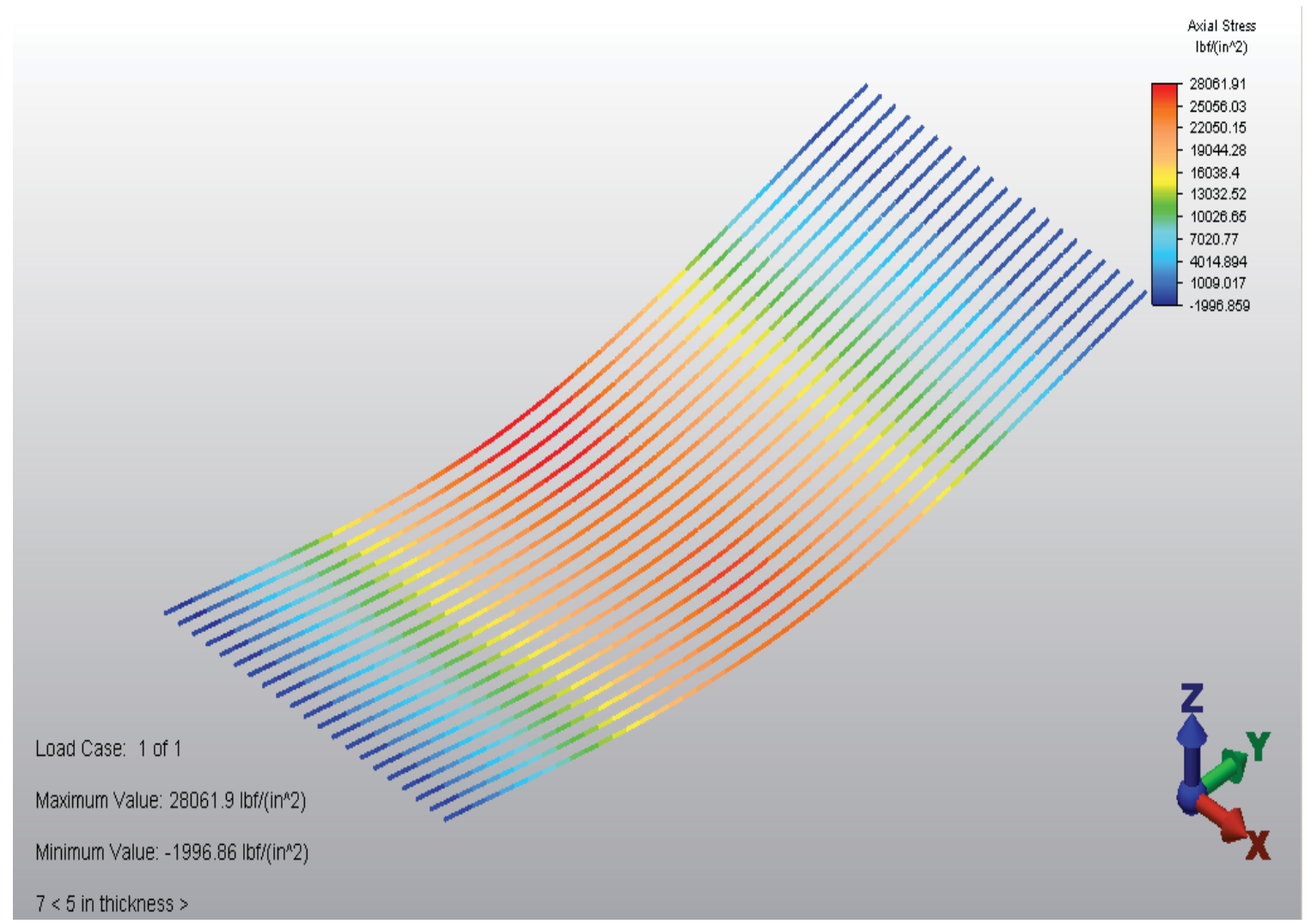

Figure 4.5C - FE Model B showing results of stresses in bottom reinforcement. 


\section{CHAPTER 5}

\section{DISCUSSION OF RESULTS}

Approach slabs are placed at the ends of bridges to ensure a smooth transition of vehicles between a bridge and pavement, as shown earlier in Fig. 2.1. When the approach slab does not perform as intended, bumps can form. There are two basic ways that bumps can form - by structural failure, or by settlement, or by a combination of both. When an approach slab fails, it bends or breaks and takes a concave shape, as shown in Fig 5.1, which results in a bumpy ride. A sleeper slab is usually placed under an approach slab at the interface with the pavement. Excessive settlement of the sleeper slab can also result in the formation of bumps even though the approach slab has not failed, as shown in Fig. 5.2.

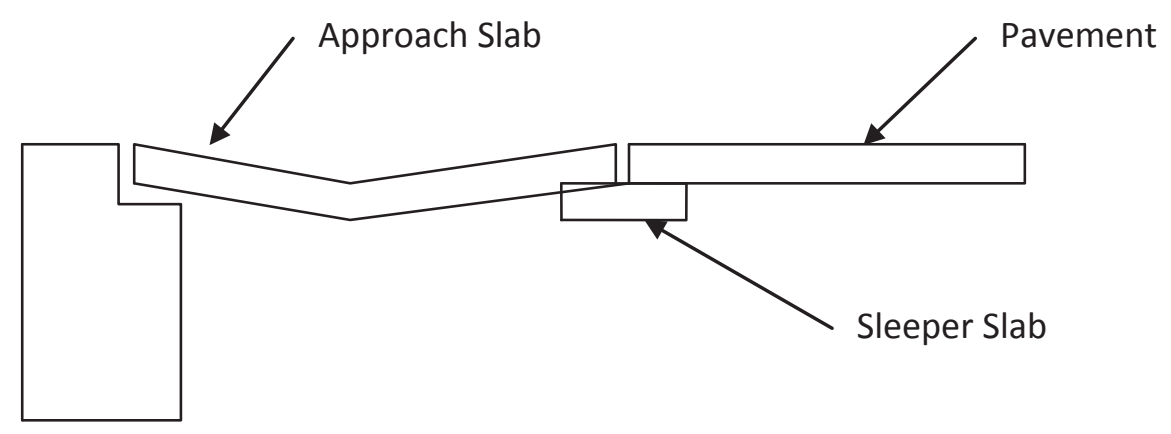

Figure 5.1 - Formation of bump due to failure of approach slab. 


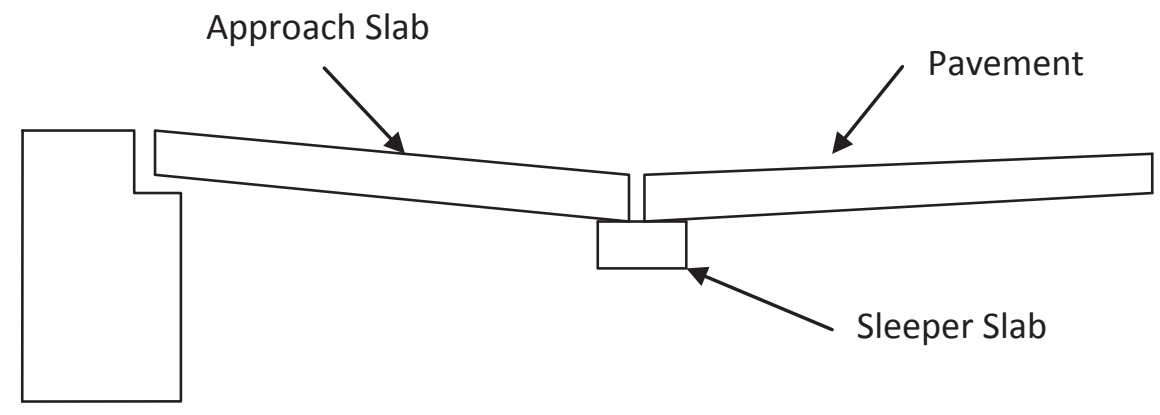

Figure 5.2 - Bump formation due to excessive settlement of sleeper slab.

Structural hand calculations were performed on the approach slab, assuming it as a simple beam with no soil support underneath, and the results summarized in Table 4.1. The adequacy of the design was evaluated by comparing the calculated internal moment capacity $\left(\Phi M_{n}\right)$ to the maximum applied moment $\left(\mathrm{M}_{\mathrm{u}}\right)$ due to HL-93 truck loading. The results indicate that approach slab designs (in new condition) recommended by state DOTs in Kentucky, Ohio and Pennsylvania were adequate to withstand applied HL-93 truck load. The Ohio DOT design showed the highest internal moment capacity of the seven evaluated, at $102.4 \mathrm{kip} \cdot \mathrm{ft} / \mathrm{ft}$. This exceeds the calculated applied moment of $74.17 \mathrm{kip} \cdot \mathrm{ft} / \mathrm{ft}$ by $28.23 \mathrm{kip} \cdot \mathrm{ft} / \mathrm{ft}$, or $38 \%$, indicating that an approach slab in new condition should not fail even if soil support underneath the slab is lost completely.

The structural hand calculations indicate that designs recommended by state DOTs in Arizona, Florida, Indiana and Michigan would be inadequate and 
would fail quickly, even in new condition, if soil support is lost. The most significant deficiency, on both an absolute and a percentage basis, is for the Florida DOT approach slab design. The calculated internal moment capacity is $65.74 \mathrm{kip} \cdot \mathrm{ft} / \mathrm{ft}$, or $67.9 \%$, less than the applied moment of $96.79 \mathrm{kip} \cdot \mathrm{ft} / \mathrm{ft}$.

Finite element analysis performed on an approach slab of $25 \mathrm{ft}$ slab length, built according to ODOT specifications, shows that when proper soil support is maintained, deflections are modest (maximum of 0.19 in). However, when soil support is lost, the predicted maximum deflection is much larger (1.34 in). After thousands of repeated HL-93 truck loadings, it is likely that the approach slab will be d amaged and develop cracks, reducing its structural capacity and eventually leading to failure. Therefore, based on the structural analysis performed in this study, and a review of the literature, bump problems at the bridge-pavement interface seem to occur primarily when soil support beneath the approach slab is lost or reduced.

Solutions to the bump problem must focus on designing, constructing and maintaining better soil support for approach slabs. Results of soil analyses performed in this study show that more severe bumps occur where soils are higher in silt and clay. This result is not surprising, and is consistent with basic geotechnical engineering principles and practice. However, it may indicate that design engineers do not adequately consider the limitations of existing soils on a bridge site. The investigation of improved geotechnical practices in bridge design and construction was not part of the scope of this study. However, the studies by 
Briaud et al. [2] and Puppala et al. [6] described in Chapter 2 point to some possible solutions.

First, better practices should be developed to properly compact the soil underneath the approach slab and sleeper slab. Where high silt/clay content and/or site geometry prevent adequate compaction of the existing soil, it should be excavated and replaced with coarser grained material. In addition, water from bridges should be diverted so that the soil underneath the approach slab does not erode due to the flow of the water. Research is needed to compare the success of current practices and develop new, innovative methods for maintaining adequate soil support for the life of an approach slab. 


\section{CHAPTER 6}

\section{CONCLUSIONS AND RECOMMENDATIONS}

Based on the results of this study, the following conclusions were drawn:

1. New approach slabs designed according to Kentucky, Ohio, and Pennsylvania DOT standards will be adeq uate to withstand applied HL-93 truck loading even if all soil support is lost.

2. New approach slabs designed according to Arizona, Florida, Indiana, and Michigan DOT standards will not be adequate to withstand applied HL-93 truck loading if all soil support is lost.

3. Based on finite element analysis, an appr oach slab designed according to ODOT standards with adequate soil support will experience a maximum deflection of 0.19 in when subjected to $\mathrm{HL}-93$ truck loading. If soil support is lost, the predicted maximum deflection increases to 1.34 in.

4. Analyses performed on soils from five bridge sites in Columbiana County, $\mathrm{OH}$, showed that the severity of bumps increased as the silt and clay content of soils increased.

5. Bump problems at bridge-pavement interfaces are mostly due to the loss of soil support beneath the approach slab. Efforts to reduce bumps should focus on geotechnical aspects of the design and construction. 
It is recommended that future research to prevent the formation of bumps should focus on the following topics:

1. The integration of geotechnical and structural aspects of the design; nonlinear analysis of approach slabs under dynamic loads should be conducted. A bump may be present in an approach slab. It can be reduced but it is impossible to get rid of the settlement of the approach slab completely. In this research, the soil underneath the approach slab was assumed to be completely lost. In reality, there is always some soil present underneath the approach slab, which provides its structural stability. This could be an added strength for the newly designed slab.

2. Better compaction of soils under the approach slab and/or other methods to increase the stability of soil.

3. More rigorous standards for silt and clay percentage in the soil under the approach slab.

4. Improved standards/practices for drainage of runoff from bridges to prevent soil erosion leading to a reduction in approach slab support. 


\section{REFERENCES}

1. Stark, T.D., Olson, S. M., Long, J.H. (1995). "Differential Movement at the Embankment/Structure Interface - Mitigation and R ehabilitation," Report No. IAB-H1, FY 93, Illinois Department of Transportation, Springfield, Illinois.

2. Wahls, H. E. (1990). "NCHRP Synthesis of Highway Practice 159: Design and Construction of Bridge Approaches," Transportation Research Board, National Research Council, Washington D.C., 45 pp.

3. Briaud, J. L., James, R. W., and Hoffman, S. B. (1997). NCHRP synthesis 234: "Settlement of Bridge Approaches (the bump at the end of the bridge)," Transportation Research Board, National Research Council, Washington, D.C., 75 pp.

4. Das, S. C., Bakeer, R., Zhong, J., and Schutt, M. (1990). "Assessment of mitigation embankment settlement with pile supported approach slabs." Louisiana Transportation and Research Center, Baton Rouge, LA.

5. Schutt, Mark. "Performance of Pile Supported Approach Slabs in Southeastern Louisiana," M.S. Thesis, Tulane University, New Orleans, LA, April 1999.

6. Puppala, A. J., Saride, S., Archeewa, E., Hoyos, L. R. and Nazarian, S. (2008). "Recommendations for Design, Construction, and Maintenance of Bridge Approach Slabs: Synthesis Report." Report No. 0-6022-1, Texas Department of Transportation in Cooperation with the U.S. Department of Transportation Federal Highway Administration, 186 pp.

7. Dupont, B. and Allen, D.L. (2002). "Movements and Settlements of Highway Bridge Approaches," Report No. KTC-02-18/SPR-220-00-1F, Kentucky Transportation Cabinet, U.S. Department of Transportation, Federal Highway Administration, 79 pp.

8. Lenke, L.R. (2006). "Settlement Issues-Bridge Approach Slabs," Rep. No. NM04MNT-02, New Mexico Department of Transportation.

9. Abu-Hejleh, N., Hanneman, D., White, D.J. and Ksouri, I. (2006). "Flowfill and MSE Bridge Approaches: Performance, Cost and Recommendations for Improvements," Rep. No. CDOT-DTD-R-2006-2, Colorado Department of Transportation, Denver.

10.Seo, J., Ha, H.S. and Briaud, J.L. (2002). "Investigation of Settlement at Bridge Approach Slab Expansion Joint: Numerical Simulation and Model Tests," Rep. No. FHWA/TX-03/4147-2, Texas Transportation Institute, Texas A\&M University, College Station, Texas. 
11.Cai, C.S., Voyiadjis, G.Z., and Shi, X. (2005). "Determination of Interaction between Bridge Concrete Approach Slab and Embankment Settlement," Report No. FHWA/LA. 05/403, Louisiana Transportation Research Center, Louisiana Department of transportation, $152 \mathrm{pp}$.

12.White, D., Mohamed, M., Sritharan, S., and Suleiman, M. (2007). "Underlying Causes for Settlement of Bridge Approach Pavement Systems." Journal of Performance of Constructed Facilities, ASCE, 273282.

13. Hopkins, T.C. (1969). "Settlement of Highway Bridge Approaches and Embankment Foundations." Rep. No. KYHPR-64-17; HPR-1(4), Kentucky Transportation Center, Lexington, Kentucky.

14. Hopkins, T.C. (1973). "Settlement of Highway Bridge Approaches and Embankment Foundations." Rep. No. KYHPR-64-17; HPR-1(8), Kentucky Transportation Center, Lexington, Kentucky.

15.Das, B.M. (2006). "Principles of Geotechnical Engineering." Sixth Edition, Cengage Learning.

16. Autodesk ALGOR Simulation Professional 2010, Autodesk Inc., Pittsburgh, Pennsylvania

17. American Association of State Highway and Transportation Officials (AASHTO) LRFD Bridge Design Specifications, Third Edition, 2006. 


\section{APPENDIX A}

Table A1 - Reinforcement ratio of slab under different settlement (adopted new design for Louisiana Department of Transportation and Development (LADOTD), $\mathrm{f}_{\mathrm{c}^{\prime}}=4000$ psi and $\mathrm{f}_{\mathrm{y}}=60,000 \mathrm{psi}$ ) [11]

\begin{tabular}{|c|c|c|c|c|}
\hline \multirow{2}{*}{$\begin{array}{l}\text { Differential } \\
\text { settlement } \\
\text { (in) } \\
\end{array}$} & \multicolumn{2}{|c|}{ 40-ft. Slab } & \multicolumn{2}{|c|}{ 60-ft. Slab } \\
\hline & $\begin{array}{c}\rho \text { for thickness of } \\
18 \mathrm{in.}\end{array}$ & $\begin{array}{l}\rho \text { for thickness of } \\
24 \text { in. }\end{array}$ & $\begin{array}{c}\rho \text { for thickness of } \\
21 \mathrm{in.}\end{array}$ & $\begin{array}{c}\rho \text { for thickness of } \\
27 \text { in. }\end{array}$ \\
\hline 0 & $\begin{array}{c}0.0025 \\
\# 7 @ 16 "(\rho= \\
0.0025)\end{array}$ & $\begin{array}{c}0.0014 \\
(\rho \min =0.0018) \\
\# 6 @ 11 "(\rho= \\
0.0019)\end{array}$ & $\begin{array}{c}0.0035 \\
\# 6 @ 7 "(\rho= \\
0.0035)\end{array}$ & $\begin{array}{c}0.0022 \\
\# 6 @ 8 "(\rho= \\
0.0023)\end{array}$ \\
\hline 0.6 & $\begin{array}{c}0.0081 \\
\# 8 @ 6 "(\rho= \\
0.0088)\end{array}$ & $\begin{array}{c}0.0058 \\
\# 8 @ 6.5 " \\
(\rho=0.0058)\end{array}$ & $\begin{array}{c}0.006 \\
\# 8 @ 7 "(\rho= \\
0.0062)\end{array}$ & $\begin{array}{c}0.0046 \\
\# 8 @ 7 "(\rho= \\
0.0047)\end{array}$ \\
\hline 1.2 & $\begin{array}{c}0.0114 \\
\# 9 @ 5.5 "(\rho= \\
0.0121)\end{array}$ & $\begin{array}{c}0.0074 \\
\# 10 @ 8 "(\rho= \\
0.0076)\end{array}$ & $\begin{array}{c}0.0083 \\
\# 9 @ 6.5 "(\rho= \\
0.0085)\end{array}$ & $\begin{array}{c}0.0065 \\
\# 9 @ 6.5 "(\rho= \\
0.0065)\end{array}$ \\
\hline 2.4 & $\begin{array}{c}0.0143 \\
\# 10 @ 6.0 "(\rho= \\
0.0141)\end{array}$ & $\begin{array}{c}0.008 \\
\# 10 @ 8.5 "(\rho= \\
0.0081)\end{array}$ & $\begin{array}{c}0.0121 \\
\# 10 @ 5.5 "(\rho= \\
0.0128)\end{array}$ & $\begin{array}{c}0.0093 \\
\# 10 @ 5.5 "(\rho= \\
0.0096)\end{array}$ \\
\hline 3.6 & $\begin{array}{c}0.0151 \\
\# 10 @ 5.5 "(\rho= \\
0.0154)\end{array}$ & $\begin{array}{c}0.0081 \\
\# 10 @ 8.5 "(\rho= \\
0.0081)\end{array}$ & $\begin{array}{c}0.0151 \\
\# 10 @ 4.5 "(\rho= \\
0.0156)\end{array}$ & $\begin{array}{c}0.011 \\
\# 10 @ 4.5 "(\rho= \\
0.0117)\end{array}$ \\
\hline 4.8 & $\begin{array}{c}0.0153 \\
\# 10 @ 5.5 "(\rho= \\
0.0154)\end{array}$ & $\begin{array}{c}0.0081 \\
\# 10 @ 8.5 "(\rho= \\
0.0081)\end{array}$ & $\begin{array}{c}0.0174 \\
\# 10 @ 4 "(\rho= \\
0.0176)\end{array}$ & $\begin{array}{c}0.012 \\
\# 10 @ 4 "(\rho= \\
0.0132)\end{array}$ \\
\hline 6 & $\begin{array}{c}0.0154 \\
\# 10 @ 5.5 "(\rho= \\
0.0154)\end{array}$ & $\begin{array}{c}0.0081 \\
\# 10 @ 8.5 "(\rho= \\
0.0081)\end{array}$ & $\begin{array}{c}0.0191 \\
\# 10 @ 3.5 "(\rho= \\
0.0202)\end{array}$ & $\begin{array}{c}0.0126 \\
\# 10 @ 4 "(\rho= \\
0.0132)\end{array}$ \\
\hline 7.2 & $\begin{array}{c}0.0154 \\
\# 10 @ 5.5 "(\rho= \\
0.0154)\end{array}$ & $\begin{array}{c}0.0081 \\
\# 10 @ 8.5 "(\rho= \\
0.0081)\end{array}$ & $\begin{array}{c}0.0204 \\
\# 10 @ 3.5 "(\rho= \\
0.0202)\end{array}$ & $\begin{array}{c}0.013 \\
\# 10 @ 4 "(\rho= \\
0.0132)\end{array}$ \\
\hline
\end{tabular}


Table A2 - Design of reinforced beam (adopted new design for LADOTD, fc'= $\left.4000 \mathrm{psi}, \mathrm{f}_{\mathrm{s}}=60,000 \mathrm{psi}\right)[11]$

\begin{tabular}{|c|c|c|c|c|}
\hline \multirow{2}{*}{ Differential } & \multicolumn{2}{|c|}{ 60-ft. Span } & \multicolumn{2}{c|}{ 80-ft. Span } \\
\cline { 2 - 5 } Settlement & Interior Beam & Interior Beam & Interior Beam & Interior Beam \\
& Spaced at $16 \mathrm{ft}$. & Spaced at $12 \mathrm{ft}$. & Spaced at $16 \mathrm{ft}$. & Spaced at $12 \mathrm{ft}$. \\
\cline { 2 - 5 } & \# of \#10 Bars & \# of \#10 Bars & \# of \#11 Bars & \# of \#11 Bars \\
\hline 0 & 2 & 2 & 2 & 2 \\
\hline 0.5 & 7 & 6 & 6 & 5 \\
\hline 1 & 8 & 7 & 8 & 7 \\
\hline 2 & 12 & 10 & 10 & 11 \\
\hline 3 & 15 & 13 & 13 & 13 \\
\hline 6 & 15 & 13 & 17 & 9 \\
\hline
\end{tabular}




\section{APPENDIX B}

Calculations for AASHTO Classification of soil under approach slab of Bridge No. COL 302578

Moisture content $(\%), W=($ Mass of water/Mass of dry soil) $* 100$

Liquid Limit, LL $=\mathrm{W}(\mathrm{N} / 25)^{012}$

$$
\begin{aligned}
& =34.3 * 0.995 \\
L L & =34.1
\end{aligned}
$$

Plasticity Index $(\mathrm{PI})=$ Liquid Limit - Plastic Limit

$$
\begin{aligned}
& =34.1-24.5 \\
& =9.6
\end{aligned}
$$

Group Index $(\mathrm{GI})=\left(\mathrm{F}_{200}-35\right)[0.2+0.005(\mathrm{LL}-40)]+0.01\left(\mathrm{~F}_{200}-15\right)(\mathrm{PI}-10)$

where, $F_{200}=$ percentage passing through the No. 200 sieve

$$
\begin{aligned}
& L L=\text { Liquid Limit } \\
& P I=\text { Plasticity Index }
\end{aligned}
$$

Since Liquid Limit of is less than 40 and Plasticity Index is less than 10.

Therefore, Group index will be negative and thus $\mathrm{GI}$ is taken as 0 .

Group Index $(\mathrm{Gl})=0$

The classification for soil is A-2-4 (0). 
Calculations for AASHTO Classification of soil under approach slab of Bridge No. COL 302667

Liquid Limit, LL $=$ W $(\mathrm{N} / 25)^{012}$

$$
\begin{aligned}
& =21.7 * 0.990 \\
L L & =21.5
\end{aligned}
$$

Plasticity Index $(\mathrm{PI})=$ Liquid Limit - Plastic Limit

Since $L L=21.5$ is smaller than $P L=25.5$, therefore $\mathrm{PI}$ is negative and hence the soil is non-plastic. Group Index (GI) is also negative and taken as 0 . The classification of soil is A-3 (0).

Calculations for AASHTO Classification of soil under approach slab of Bridge No. COL $112 \mathrm{~L}$

Liquid Limit, $\mathrm{LL}=\mathrm{W}(\mathrm{N} / 25)^{012}$

$$
\begin{aligned}
& =26.3 * 0.948 \\
L L & =24.9
\end{aligned}
$$

Plasticity Index $(\mathrm{PI})=$ Liquid Limit $(\mathrm{LL})-$ Plastic Limit $(\mathrm{PL})$

$$
\begin{aligned}
& =24.9-21.5 \\
& =3.4
\end{aligned}
$$

Group Index is also negative since LL is less than 40 and PI is less than 10 and thus $\mathrm{GI}$ is taken as 0 . The classification of soil is $A-1-b(0)$. 
Calculations for AASHTO Classification of soil under approach slab of Bridge No. COL 302670

Liquid Limit, LL $=W(N / 25)^{012}$

$$
\begin{aligned}
& =35 * 0.961 \\
L L & =33.6
\end{aligned}
$$

Plasticity Index $(\mathrm{PI})=$ Liquid Limit $(\mathrm{LL})-$ Plastic Limit $(\mathrm{PL})$

$$
\begin{aligned}
& =33.6-30.7 \\
& =2.9
\end{aligned}
$$

Group Index $(\mathrm{Gl})$ is negative and taken as 0 . The classification of the soil is A-1-b (0).

Calculations for AASHTO Classification of soil under approach slab of Bridge No. COL 303182

Liquid Limit, $\mathrm{LL}=\mathrm{W}(\mathrm{N} / 25)^{012}$

$$
\begin{aligned}
& =31.8 * 1.014 \\
L L & =32.2
\end{aligned}
$$

Plasticity Index (PI) is negative since Plastic Limit is greater than Liquid Limit. Therefore, soil is non-plastic. Also, Group index is negative too and taken as 0 . The classification of the soil is A-3 (0). 


\section{APPENDIX C}

Calculations for maximum applied moment per feet of approach slab from ALGOR Model B

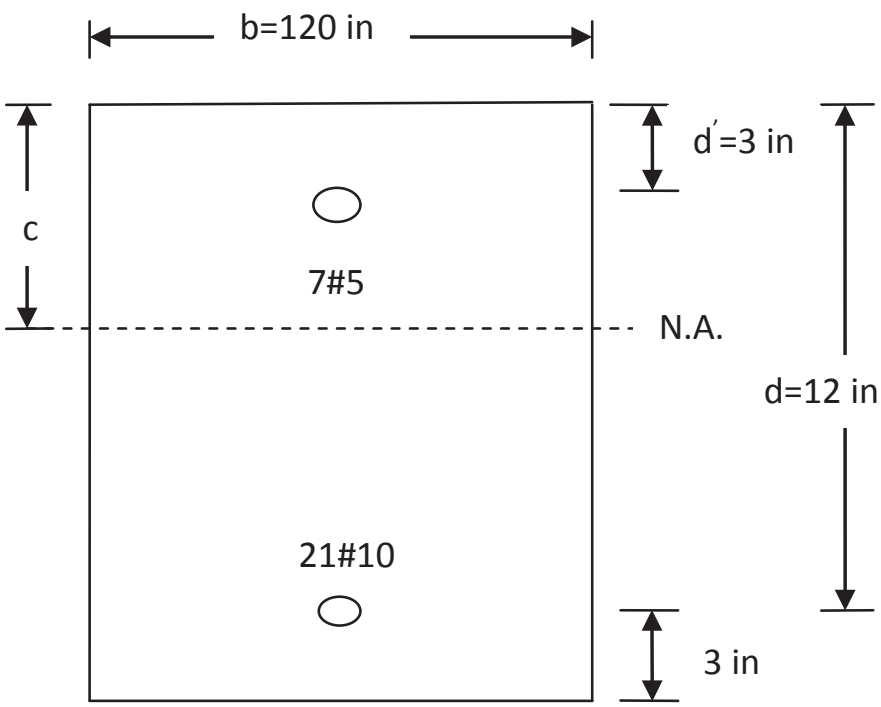

Figure C.1 - Cross-section of approach slab model.

$$
\begin{aligned}
& A_{s}=\left(21^{*} 1.27\right)=26.67 \mathrm{in}^{2} \\
& A_{s^{\prime}}=\left(7^{*} 0.31\right)=2.17 \mathrm{in}^{2}
\end{aligned}
$$

Modulus of Elasticity of concrete $\left(E_{c}\right)=3000 \mathrm{ksi}$

Modulus of Elasticity of steel $\left(E_{s}\right)=29000 \mathrm{ksi}$

Modular ratio $(n)=E_{s} / E_{c}=29000 / 3000$

$$
=10
$$

\section{Locating neutral axis (c):}

$$
\begin{aligned}
& 120^{*} c^{*}(c / 2)+(2 n-1)^{*} A_{s^{*}}{ }^{*}(c-3)=n^{*} A_{s}{ }^{*}(12-c) \\
& 60 c^{2}+19^{*} 2.17^{*}(c-3)=10^{*} 26.67^{*}(12-c) \\
& 60 c^{2}+307.93 c-3324.09=0
\end{aligned}
$$


$c=5.307$ in

Neutral axis was taken as 5 in for ALGOR model due to meshing.

Effective moment of Inertia $\left(l_{\text {eff }}\right)=\left(b^{*} c^{3}\right) / 3+(2 n-1)^{*} A_{s}{ }^{*}(c-3)^{2}+n^{*} A_{s}{ }^{*}(12-c)^{2}$

$$
\begin{aligned}
& =\left(120^{\star} 5^{3}\right) / 3+19^{\star} 2 \cdot 17^{\star} 2^{2}+10^{\star} 26 \cdot 67^{\star} 7^{2} \\
& =18,233.22 \mathrm{in}^{4}
\end{aligned}
$$

Stress in bottom reinforcement from ALGOR $\left(f_{s}\right)=28,062 p s i$

Applied moment per feet $(M)=\left\{\left.\mathrm{f}_{\mathrm{s}}{ }^{*}\right|_{\text {efff }}\right\} /\left\{10^{*} \mathrm{n}^{*}(12-\mathrm{c})\right\}$

$$
\begin{aligned}
& =\{28062 * 18233.22\} /\left\{10^{*} 10^{*} 7\right\} \\
& =60.92 \mathrm{kip}-\mathrm{ft} / \mathrm{ft}
\end{aligned}
$$




\section{Calculations for Design Moment Capacity of approach slab using Ohio DOT specifications}

Beam dimension:

$\mathrm{b}:=120 \cdot$ in

$\mathrm{h}:=15 \cdot$ in

$\mathrm{C}_{\mathrm{c}}:=3 \cdot$ in

$\mathrm{d}^{\prime}:=3 \cdot$ in

$\mathrm{d}:=\mathrm{h}-\mathrm{C}_{\mathrm{c}}$
Material properties:

$$
\begin{array}{ll}
\gamma_{\mathrm{c}}:=0.15 \cdot \frac{\mathrm{kip}}{\mathrm{ft}^{3}} & \mathrm{f}_{\mathrm{y}}:=60 \cdot \mathrm{ksi} \\
\mathrm{E}:=29000 \cdot \mathrm{ksi} & \mathrm{f}_{\mathrm{c}}:=4.5 \cdot \mathrm{ksi} \\
\phi:=0.9 &
\end{array}
$$$$
\underset{M M}{L}:=25 \cdot \mathrm{ft}
$$

Assume

$$
\underset{M}{c}:=1 \cdot \text { in }
$$

Given

$$
\begin{aligned}
& A_{s} \cdot f_{y}=\left(0.85 \cdot f_{c} \cdot 0.825 \cdot c \cdot b\right)+A_{s^{\prime}} \cdot \frac{\left(c-d^{\prime}\right)}{c} \cdot 0.003 \cdot E \\
& \underset{\mathrm{c}}{\mathrm{c}}:=\operatorname{Find}(\mathrm{c}) \quad \mathrm{c}=3.39 \cdot \mathrm{in} \\
& \mathrm{a}:=0.825 \cdot \mathrm{c} \quad \mathrm{a}=2.8 \cdot \mathrm{in} \\
& \mathrm{f}_{\mathrm{s}^{\prime}}:=\frac{\left|\mathrm{c}-\mathrm{d}^{\prime}\right|}{\mathrm{c}} \cdot 0.003 \cdot \mathrm{E} \quad \mathrm{f}_{\mathrm{S}^{\prime}}=10.09 \cdot \mathrm{ksi}
\end{aligned}
$$

CheckCompressionSteel := if $\left(\mathrm{f}_{\mathrm{s}^{\prime}}<\mathrm{f}_{\mathrm{y}}\right.$, "Compression Steel Not Yielding" , "Compression Steel Yielding" $)$

CheckCompressionSteel = "Compression Steel Not Yielding"
$A_{\mathrm{s} 2}:=\frac{A_{s^{\prime}} \cdot f_{\mathrm{s}^{\prime}}}{f_{y}}$
$\mathrm{A}_{\mathrm{s} 2}=0.35 \cdot \mathrm{in}^{2}$
$\mathrm{A}_{\mathrm{s} 1}:=\mathrm{A}_{\mathrm{s}}-\mathrm{A}_{\mathrm{s} 2}$
$\mathrm{A}_{\mathrm{s} 1}=21.42 \cdot \mathrm{in}^{2}$
$\varepsilon_{\mathrm{t}}:=\frac{\mathrm{d}-\mathrm{c}}{\mathrm{c}} \cdot 0.003$
$\varepsilon_{\mathrm{t}}=0.00761$

CheckTensionSteel $:=\operatorname{if}\left(\varepsilon_{\mathrm{t}}>0.005\right.$, "OK, Tension Steel Yielding Governs Failure" , "No Good,Revise Section" $)$

CheckTensionSteel $=$ "OK, Tension Steel Yielding Governs Failure" 
Internal moment capacity per feet width of approach slab,

$$
\begin{aligned}
\phi \mathrm{M}_{\mathrm{n}} & :=\frac{\phi \cdot\left[\mathrm{A}_{\mathrm{s} 1} \cdot \mathrm{f}_{\mathrm{y}} \cdot(\mathrm{d}-0.5 \cdot \mathrm{a})+\mathrm{A}_{\mathrm{s} 2} \cdot \mathrm{f}_{\mathrm{s}^{\prime}} \cdot\left(\mathrm{d}-\mathrm{d}^{\prime}\right)\right]}{\mathrm{b}} \\
\phi \mathrm{M}_{\mathrm{n}} & =102.4 \cdot \mathrm{kip} \cdot \frac{\mathrm{ft}}{\mathrm{ft}}
\end{aligned}
$$




\section{Moment calculations for Arizona DOT drawings}

\section{Beam dimension: Material properties:}

$\mathrm{b}:=120 \cdot$ in

$$
\mathrm{A}_{\mathrm{S}^{\prime}}:=1.33 \cdot \mathrm{in}^{2}
$$

$$
\gamma_{\mathrm{c}}:=0.15 \cdot \frac{\mathrm{kip}}{\mathrm{ft}^{3}}
$$$$
f_{y}:=60 \cdot k s i
$$

$\mathrm{h}:=12 \cdot \mathrm{in}$

$\mathrm{C}_{\mathrm{c}}:=3 \cdot$ in

$\mathrm{d}^{\prime}:=2.5 \cdot$ in

$\mathrm{A}_{\mathrm{S}}:=10.53 \cdot \mathrm{in}^{2}$

$\mathrm{W}_{\mathrm{S}}:=1.75 \cdot$ in

$$
\mathrm{E}:=29000 \cdot \mathrm{ksi} \quad \mathrm{f}_{\mathrm{c}}:=3 \cdot \mathrm{ksi}
$$

$\mathrm{d}:=\mathrm{h}-\mathrm{C}_{\mathrm{c}}$

$$
\underset{M A}{L}:=15 \cdot \mathrm{ft}
$$

$\phi:=0.9$

Assume

$$
\underset{M}{c}:=1 \cdot \mathrm{mm}
$$

Given

$$
\begin{aligned}
& A_{s} \cdot f_{y}=\left(0.85 \cdot f_{c} \cdot 0.85 \cdot c \cdot b\right)+A_{s} \cdot \frac{\left(c-d^{\prime}\right)}{c} \cdot 0.003 \cdot E \\
& \mathrm{c}:=\operatorname{Find}(\mathrm{c}) \\
& \mathrm{c}=2.44 \cdot \text { in } \\
& \mathrm{a}:=0.85 \cdot \mathrm{c} \\
& \mathrm{a}=2.07 \cdot \mathrm{in} \\
& \mathrm{f}_{\mathrm{S}^{\prime}}:=\frac{\left|\mathrm{c}-\mathrm{d}^{\prime}\right|}{\mathrm{c}} \cdot 0.003 \cdot \mathrm{E} \\
& \mathrm{f}_{\mathrm{S}^{\prime}}=2.14 \cdot \mathrm{ksi}
\end{aligned}
$$

CheckCompressionSteel := if $\left(\mathrm{f}_{\mathrm{s}^{\prime}}<\mathrm{f}_{\mathrm{y}}\right.$, "Compression Steel Not Yielding" , "Compression Steel Yielding" $)$

CheckCompressionSteel $=$ "Compression Steel Not Yielding"

$$
\begin{array}{ll}
\mathrm{A}_{\mathrm{s} 2}:=\frac{\mathrm{A}_{\mathrm{s}} \cdot \mathrm{f}_{\mathrm{s}}}{\mathrm{f}_{\mathrm{y}}} & \mathrm{A}_{\mathrm{s} 2}=0.05 \cdot \mathrm{in}^{2} \\
\mathrm{~A}_{\mathrm{s} 1}:=\mathrm{A}_{\mathrm{s}}-\mathrm{A}_{\mathrm{s} 2} & \mathrm{~A}_{\mathrm{s} 1}=10.48 \cdot \mathrm{in}^{2} \\
\varepsilon_{\mathrm{t}}:=\frac{\mathrm{d}-\mathrm{c}}{\mathrm{c}} \cdot 0.003 & \varepsilon_{\mathrm{t}}=0.00807 \\
\mathrm{M}_{\mathrm{LL}}:=(16 \cdot \mathrm{kip}) \cdot(0.5 \cdot \mathrm{L}) & \mathrm{M}_{\mathrm{DL}}:=0.125 \cdot \mathrm{b} \cdot\left(\mathrm{h}+\mathrm{W}_{\mathrm{s}}\right) \cdot \gamma_{\mathrm{c}} \cdot \mathrm{L}^{2} \\
\mathrm{M}_{\mathrm{LL}}=120 \cdot \mathrm{kip} \cdot \mathrm{ft} & \mathrm{M}_{\mathrm{DL}}=48.34 \cdot \mathrm{kip} \cdot \mathrm{ft}
\end{array}
$$


CheckTensionSteel $:=\operatorname{if}\left(\varepsilon_{\mathrm{t}}>0.005\right.$, "OK, Tension Steel Yielding Governs Failure" , No Good,Revise Section" $)$

CheckTensionSteel = "OK, Tension Steel Yielding Governs Failure"

Applied bending moment per feet width of approach slab,

$$
\begin{aligned}
& \mathrm{M}_{\mathrm{u}}:=\frac{\left(1.25 \cdot \mathrm{M}_{\mathrm{DL}}+1.75 \cdot 1.33 \cdot 1.2 \cdot \mathrm{M}_{\mathrm{LL}}\right)}{\mathrm{b}} \\
& \mathrm{M}_{\mathrm{u}}=39.56 \cdot \mathrm{kip} \cdot \frac{\mathrm{ft}}{\mathrm{ft}}
\end{aligned}
$$

Internal moment capacity per feet width of approach slab,

$$
\begin{aligned}
\phi M_{n} & :=\frac{\phi \cdot\left[A_{s 1} \cdot f_{y} \cdot(d-0.5 \cdot a)+A_{s} \cdot f_{s} \cdot\left(d-d^{\prime}\right)\right]}{b} \\
\phi M_{n} & =37.7 \cdot \operatorname{kip} \cdot \frac{\mathrm{ft}}{\mathrm{ft}}
\end{aligned}
$$




\section{Moment calculations for Florida DOT drawing}

\section{Beam dimension:}

$\mathrm{b}:=120 \cdot$ in

$\mathrm{h}:=12 \cdot$ in

$\mathrm{C}_{\mathrm{c}}:=4 \cdot$ in

$\mathrm{d}^{\prime}:=2.5 \cdot$ in

$\mathrm{d}:=\mathrm{h}-\mathrm{C}_{\mathrm{c}}$
Material properties:

$$
\begin{array}{lll}
\mathrm{A}_{\mathrm{S}^{\prime}}:=3.1 \cdot \mathrm{in}^{2} & \gamma_{\mathrm{c}}:=0.15 \cdot \frac{\mathrm{kip}}{\mathrm{ft}^{3}} & \mathrm{f}_{\mathrm{y}}:=60 \cdot \mathrm{ksi} \\
\mathrm{A}_{\mathrm{S}}:=10.53 \cdot \mathrm{in}^{2} & \mathrm{E}:=29000 \cdot \mathrm{ksi} & \mathrm{f}_{\mathrm{c}}:=4.5 \cdot \mathrm{ksi} \\
\mathrm{W}_{\mathrm{S}}:=1.75 \cdot \mathrm{in} & \phi:=0.9 & \\
\mathrm{~L}_{M}:=30 \cdot \mathrm{ft} &
\end{array}
$$

Assume

$$
\underset{M M}{c}:=1 \cdot \text { in }
$$

Given

$$
\begin{aligned}
& A_{s} \cdot f_{y}=\left(0.85 \cdot f_{c} \cdot 0.85 \cdot c \cdot b\right)+A_{s^{\prime}} \cdot \frac{\left(c-d^{\prime}\right)}{c} \cdot 0.003 \cdot E \\
& \underset{M M}{c}:=\operatorname{Find}(\mathrm{c}) \\
& \mathrm{c}=1.86 \cdot \text { in } \\
& \mathrm{a}:=0.85 \cdot \mathrm{c} \\
& \mathrm{a}=1.58 \cdot \mathrm{in} \\
& \mathrm{f}_{\mathrm{s}^{\prime}}:=\frac{\left|\mathrm{c}-\mathrm{d}^{\prime}\right|}{\mathrm{c}} \cdot 0.003 \cdot \mathrm{E} \quad \mathrm{f}_{\mathrm{S}^{\prime}}=30.05 \cdot \mathrm{ksi}
\end{aligned}
$$

CheckCompressionSteel $:=\operatorname{if}\left(\mathrm{f}_{\mathrm{s}^{\prime}}<\mathrm{f}_{\mathrm{y}}\right.$, "Compression Steel Not Yielding" , "Compression Steel Yielding" $)$

CheckCompressionSteel $=$ "Compression Steel Not Yielding"

$$
\begin{array}{ll}
\mathrm{A}_{\mathrm{s} 2}:=\frac{\mathrm{A}_{\mathrm{s}^{\prime}} \cdot \mathrm{f}_{\mathrm{S}}}{\mathrm{f}_{\mathrm{y}}} \quad \mathrm{A}_{\mathrm{s} 2}=1.55 \cdot \mathrm{in}^{2} & \mathrm{~A}_{\mathrm{S} 1}=8.98 \cdot \mathrm{in}^{2} \\
\mathrm{~A}_{\mathrm{S} 1}:=\mathrm{A}_{\mathrm{S}}-\mathrm{A}_{\mathrm{S} 2} & \varepsilon_{\mathrm{t}}=0.00992 \\
\varepsilon_{\mathrm{t}}:=\frac{\mathrm{d}-\mathrm{c}}{\mathrm{c}} \cdot 0.003 & \\
\mathrm{M}_{\mathrm{LL}}:=16.8 \cdot \mathrm{kip} \cdot(0.5 \cdot \mathrm{L}-1 \cdot \mathrm{ft})+24.8 \cdot \mathrm{kip} \cdot(0.5 \cdot \mathrm{L}-14 \cdot \mathrm{ft}) \\
\mathrm{M}_{\mathrm{DL}}:=0.125 \cdot \mathrm{b} \cdot\left(\mathrm{h}+\mathrm{W}_{\mathrm{S}}\right) \cdot \gamma_{\mathrm{c}} \cdot \mathrm{L}^{2} \\
\mathrm{M}_{\mathrm{LL}}=260 \cdot \mathrm{kip} \cdot \mathrm{ft} \quad \quad \mathrm{M}_{\mathrm{DL}}=193.36 \cdot \mathrm{kip} \cdot \mathrm{ft}
\end{array}
$$


CheckTensionSteel $:=\operatorname{if}\left(\varepsilon_{\mathrm{t}}>0.005\right.$, "OK, Tension Steel Yielding Governs Failure" , "No Good,Revise Section" $)$

CheckTensionSteel = "OK, Tension Steel Yielding Governs Failure"

Applied bending moment per feet width of approach slab,

$$
\begin{aligned}
& \mathrm{M}_{\mathrm{u}}:=\frac{\left(1.25 \cdot \mathrm{M}_{\mathrm{DL}}+1.75 \cdot 1.33 \cdot 1.2 \cdot \mathrm{M}_{\mathrm{LL}}\right)}{\mathrm{b}} \\
& \mathrm{M}_{\mathrm{u}}=96.79 \cdot \mathrm{kip} \cdot \frac{\mathrm{ft}}{\mathrm{ft}}
\end{aligned}
$$

Internal moment capacity per feet width of approach slab,

$$
\begin{aligned}
\phi M_{n} & :=\frac{\phi \cdot\left[A_{\mathrm{s} 1} \cdot f_{y} \cdot(d-0.5 \cdot a)+A_{s} \cdot f_{s} \cdot\left(d-d^{\prime}\right)\right]}{b} \\
\phi M_{n} & =31.05 \cdot k i p \cdot \frac{f t}{f t}
\end{aligned}
$$




\section{Moment calculations for Indiana DOT drawing}

\section{Beam dimension:}

$\mathrm{b}:=120 \cdot$ in

$\mathrm{h}:=10 \cdot$ in

$\mathrm{C}_{\mathrm{c}}:=2 \cdot$ in

$\mathrm{d}^{\prime}:=2.5 \cdot$ in

$\mathrm{d}:=\mathrm{h}-\mathrm{C}_{\mathrm{c}}$
Material properties:

$$
\begin{aligned}
& \mathrm{A}_{\mathrm{S}^{\prime}}:=2.03 \cdot \mathrm{in}^{2} \\
& \mathrm{~A}_{\mathrm{S}}:=6.30 \cdot \mathrm{in}^{2} \\
& \mathrm{~W}_{\mathrm{S}}:=1.75 \cdot \mathrm{in} \\
& \mathrm{L}_{M}:=20 \cdot \mathrm{ft}
\end{aligned}
$$$$
\gamma_{\mathrm{c}}:=0.15 \cdot \frac{\mathrm{kip}}{\mathrm{ft}^{3}}
$$$$
\mathrm{f}_{\mathrm{y}}:=60 \cdot \mathrm{ksi}
$$$$
\mathrm{E}:=29000 \cdot \mathrm{ksi}
$$$$
\mathrm{f}_{\mathrm{c}}:=4 \cdot \mathrm{ksi}
$$$$
\phi:=0.9
$$

Assume

$$
\stackrel{c}{c}:=1 \cdot \text { in }
$$

Given

$$
\begin{aligned}
& A_{s} \cdot f_{y}=\left(0.85 \cdot f_{c} \cdot 0.85 \cdot c \cdot b\right)+A_{s} \cdot \frac{\left(c-d^{\prime}\right)}{c} \cdot 0.003 \cdot E \\
& \underset{M M}{c}:=\operatorname{Find}(\mathrm{c}) \\
& \mathrm{c}=1.46 \cdot \mathrm{in} \\
& \mathrm{a}:=0.85 \cdot \mathrm{c} \\
& \mathrm{a}=1.24 \cdot \mathrm{in} \\
& \mathrm{f}_{\mathrm{s}^{\prime}}:=\frac{\left|\mathrm{c}-\mathrm{d}^{\prime}\right|}{\mathrm{c}} \cdot 0.003 \cdot \mathrm{E} \\
& \mathrm{f}_{\mathrm{s}^{\prime}}=62.44 \cdot \mathrm{ksi}
\end{aligned}
$$

CheckCompressionSteel $:=\operatorname{if}\left(\mathrm{f}_{\mathrm{s}^{\prime}}<\mathrm{f}_{\mathrm{y}}\right.$, "Compression Steel Not Yielding" , "Compression Steel Yielding" $)$

CheckCompressionSteel $=$ "Compression Steel Yielding"
$A_{\mathrm{s} 2}:=\frac{A_{s^{\prime}} \cdot f_{\mathrm{s}^{\prime}}}{f_{y}}$
$\mathrm{A}_{\mathrm{s} 2}=2.11 \cdot \mathrm{in}^{2}$
$\mathrm{A}_{\mathrm{s} 1}:=\mathrm{A}_{\mathrm{s}}-\mathrm{A}_{\mathrm{s} 2}$
$\mathrm{A}_{\mathrm{s} 1}=4.19 \cdot \mathrm{in}^{2}$
$\varepsilon_{\mathrm{t}}:=\frac{\mathrm{d}-\mathrm{c}}{\mathrm{c}} \cdot 0.003$
$\varepsilon_{\mathrm{t}}=0.01349$

$$
\begin{array}{ll}
\mathrm{M}_{\mathrm{LL}}:=(16 \cdot \mathrm{kip}) \cdot(0.5 \cdot \mathrm{L}) & \mathrm{M}_{\mathrm{DL}}:=0.125 \cdot \mathrm{b} \cdot(\mathrm{h}) \cdot \gamma_{\mathrm{c}} \cdot \mathrm{L}^{2} \\
\mathrm{M}_{\mathrm{LL}}=160 \cdot \mathrm{kip} \cdot \mathrm{ft} & \mathrm{M}_{\mathrm{DL}}=62.5 \cdot \mathrm{kip} \cdot \mathrm{ft}
\end{array}
$$


CheckTensionSteel $:=\operatorname{if}\left(\varepsilon_{\mathrm{t}}>0.005\right.$, "OK, Tension Steel Yielding Governs Failure" , No Good,Revise Section" $)$

CheckTensionSteel = "OK, Tension Steel Yielding Governs Failure"

Applied bending moment per feet width of approach slab,

$$
\begin{aligned}
\mathrm{M}_{\mathrm{u}} & :=\frac{\left(1.25 \cdot \mathrm{M}_{\mathrm{DL}}+1.75 \cdot 1.33 \cdot 1.2 \cdot \mathrm{M}_{\mathrm{LL}}\right)}{\mathrm{b}} \\
\mathrm{M}_{\mathrm{u}} & =52.5 \cdot \mathrm{kip} \cdot \frac{\mathrm{ft}}{\mathrm{ft}}
\end{aligned}
$$

Internal moment capacity per feet width of approach slab,

$$
\begin{aligned}
\phi M_{n} & :=\frac{\phi \cdot\left[A_{s 1} \cdot f_{y} \cdot(d-0.5 \cdot a)+A_{s} \cdot f_{y} \cdot\left(d-d^{\prime}\right)\right]}{b} \\
\phi M_{n} & =19.14 \cdot k i p \cdot \frac{f t}{f t}
\end{aligned}
$$




\section{Moment calculations for Kentucky DOT drawing}

\section{Beam dimension:}

$$
\begin{aligned}
& \mathrm{b}:=120 \cdot \text { in } \\
& \mathrm{h}:=17 \cdot \text { in } \\
& \mathrm{C}_{\mathrm{c}}:=3 \cdot \text { in } \\
& \mathrm{d}^{\prime}:=0 \cdot \text { in } \\
& \mathrm{d}:=\mathrm{h}-\mathrm{C}_{\mathrm{c}}
\end{aligned}
$$

Material properties:

$$
\begin{aligned}
& \mathrm{A}_{\mathrm{S}^{\prime}}:=0 \cdot \mathrm{in}^{2} \\
& \mathrm{~A}_{\mathrm{S}}:=15.8 \cdot \mathrm{in}^{2} \\
& \mathrm{~W}_{\mathrm{S}}:=1.75 \cdot \mathrm{in} \\
& \mathrm{LM}_{M}:=25 \cdot \mathrm{ft}
\end{aligned}
$$$$
\gamma_{\mathrm{c}}:=0.15 \cdot \frac{\mathrm{kip}}{\mathrm{ft}^{3}}
$$$$
\mathrm{f}_{\mathrm{y}}:=60 \cdot \mathrm{ksi}
$$$$
\mathrm{E}:=29000 \cdot \mathrm{ksi}
$$$$
\mathrm{f}_{\mathrm{c}}:=3.5 \cdot \mathrm{ksi}
$$$$
\phi:=0.9
$$

Assume

$$
\stackrel{c}{c}:=1 \cdot \text { in }
$$

Given

$$
\begin{array}{ll}
\mathrm{A}_{\mathrm{s}} \cdot \mathrm{f}_{\mathrm{y}}=\left(0.85 \cdot \mathrm{f}_{\mathrm{c}} \cdot 0.85 \cdot \mathrm{c} \cdot \mathrm{b}\right)+\mathrm{A}_{\mathrm{s}^{\prime}} \cdot \frac{\left(\mathrm{c}-\mathrm{d}^{\prime}\right)}{\mathrm{c}} \cdot 0.003 \cdot \mathrm{E} \\
\mathrm{c}_{\mathrm{M}}:=\operatorname{Find}(\mathrm{c}) & \mathrm{c}=3.12 \cdot \mathrm{in} \\
\mathrm{a}:=0.85 \cdot \mathrm{c} & \mathrm{a}=2.66 \cdot \mathrm{in} \\
\mathrm{f}_{\mathrm{s}^{\prime}}:=\frac{\left|\mathrm{c}-\mathrm{d}^{\prime}\right|}{\mathrm{c}} \cdot 0.003 \cdot \mathrm{E} & \mathrm{f}_{\mathrm{s}^{\prime}}=87 \cdot \mathrm{ksi}
\end{array}
$$

CheckCompressionSteel := if $\left(\mathrm{f}_{\mathrm{s}^{\prime}}<\mathrm{f}_{\mathrm{y}}\right.$, "Compression Steel Not Yielding" , "Compression Steel Yielding" $)$

CheckCompressionSteel $=$ "Compression Steel Yielding"
$A_{\mathrm{s} 2}:=\frac{A_{s^{\prime}} \cdot f_{\mathrm{s}^{\prime}}}{f_{y}}$
$\mathrm{A}_{\mathrm{s} 2}=0 \cdot \mathrm{in}^{2}$
$\mathrm{M}_{\mathrm{LL}}:=(16 \cdot \mathrm{kip}) \cdot(0.5 \cdot \mathrm{L})$
$\mathrm{A}_{\mathrm{s} 1}:=\mathrm{A}_{\mathrm{s}}-\mathrm{A}_{\mathrm{s} 2}$
$\mathrm{A}_{\mathrm{s} 1}=15.8 \cdot \mathrm{in}^{2}$
$\mathrm{M}_{\mathrm{DL}}:=0.125 \cdot \mathrm{b} \cdot(\mathrm{h}) \cdot \gamma_{\mathrm{c}} \cdot \mathrm{L}^{2}$
$\varepsilon_{\mathrm{t}}:=\frac{\mathrm{d}-\mathrm{c}}{\mathrm{c}} \cdot 0.003$
$\varepsilon_{\mathrm{t}}=0.01044$
$\mathrm{M}_{\mathrm{LL}}=200 \cdot \mathrm{kip} \cdot \mathrm{ft}$
$\mathrm{M}_{\mathrm{DL}}=166.02 \cdot \mathrm{kip} \cdot \mathrm{ft}$ 
CheckTensionSteel $:=\operatorname{if}\left(\varepsilon_{\mathrm{t}}>0.005\right.$, "OK, Tension Steel Yielding Governs Failure" , No Good,Revise Section" $)$

CheckTensionSteel = "OK, Tension Steel Yielding Governs Failure"

Applied bending moment per feet width of approach slab,

$$
\mathrm{M}_{\mathrm{u}}:=\frac{\left(1.25 \cdot \mathrm{M}_{\mathrm{DL}}+1.75 \cdot 1.33 \cdot 1.2 \cdot \mathrm{M}_{\mathrm{LL}}\right)}{\mathrm{b}} \quad \mathrm{M}_{\mathrm{u}}=76.61 \cdot \mathrm{kip} \cdot \frac{\mathrm{ft}}{\mathrm{ft}}
$$

Internal moment capacity per feet width of approach slab,

$$
\begin{aligned}
\phi \mathrm{M}_{\mathrm{n}} & :=\frac{\phi \cdot\left[\mathrm{A}_{\mathrm{s} 1} \cdot \mathrm{f}_{\mathrm{y}} \cdot(\mathrm{d}-0.5 \cdot \mathrm{a})+\mathrm{A}_{\mathrm{s} 2} \cdot \mathrm{f}_{\mathrm{y}} \cdot\left(\mathrm{d}-\mathrm{d}^{\prime}\right)\right]}{\mathrm{b}} \\
\phi \mathrm{M}_{\mathrm{n}} & =90.1 \cdot \mathrm{kip} \cdot \frac{\mathrm{ft}}{\mathrm{ft}}
\end{aligned}
$$




\section{Moment calculations for Michigan DOT drawing}

\section{Beam dimension:}

$\mathrm{b}:=120 \cdot$ in

$\mathrm{h}:=12 \cdot$ in

$\mathrm{C}_{\mathrm{c}}:=3 \cdot$ in

$\mathrm{d}^{\prime}:=3 \cdot$ in

$\mathrm{d}:=\mathrm{h}-\mathrm{C}_{\mathrm{c}}$
Material properties:

$$
\begin{aligned}
& \mathrm{A}_{\mathrm{S}^{\prime}}:=8.95 \cdot \mathrm{in}^{2} \\
& \mathrm{~A}_{\mathrm{S}}:=8.95 \cdot \mathrm{in}^{2} \\
& \mathrm{~W}_{\mathrm{S}}:=1.75 \cdot \mathrm{in} \\
& \mathrm{L}_{M}:=20 \cdot \mathrm{ft}
\end{aligned}
$$

$$
\begin{array}{ll}
\gamma_{\mathrm{c}}:=0.15 \cdot \frac{\mathrm{kip}}{\mathrm{ft}^{3}} & \mathrm{f}_{\mathrm{y}}:=60 \cdot \mathrm{ksi} \\
\mathrm{E}:=29000 \cdot \mathrm{ksi} & \mathrm{f}_{\mathrm{c}}:=4.5 \cdot \mathrm{ksi} \\
\phi:=0.9 &
\end{array}
$$

Assume

$$
\underset{M M}{c}:=1 \cdot \text { in }
$$

Given

$$
\begin{array}{ll}
\mathrm{A}_{\mathrm{s}} \cdot \mathrm{f}_{\mathrm{y}}=\left(0.85 \cdot \mathrm{f}_{\mathrm{c}} \cdot 0.85 \cdot \mathrm{c} \cdot \mathrm{b}\right)+\mathrm{A}_{\mathrm{s}^{\prime}} \cdot \frac{\left(\mathrm{c}-\mathrm{d}^{\prime}\right)}{\mathrm{c}} \cdot 0.003 \cdot \mathrm{E} \\
\underset{M \mathrm{M}^{\mathrm{c}}:=\text { Find }(\mathrm{c})}{\mathrm{c}=2.16 \cdot \mathrm{in}} \\
\mathrm{a}:=0.85 \cdot \mathrm{c} & \mathrm{a}=1.83 \cdot \mathrm{in} \\
\mathrm{f}_{\mathrm{s}^{\prime}}:=\frac{\left|\mathrm{c}-\mathrm{d}^{\prime}\right|}{\mathrm{c}} \cdot 0.003 \cdot \mathrm{E} & \mathrm{f}_{\mathrm{s}^{\prime}}=34.02 \cdot \mathrm{ksi}
\end{array}
$$

CheckCompressionSteel $:=\operatorname{if}\left(\mathrm{f}_{\mathrm{s}^{\prime}}<\mathrm{f}_{\mathrm{y}}\right.$, "Compression Steel Not Yielding" , "Compression Steel Yielding" $)$ CheckCompressionSteel $=$ "Compression Steel Not Yielding"
$A_{\mathrm{s} 2}:=\frac{A_{s^{\prime}} \cdot f_{\mathrm{s}^{\prime}}}{f_{y}}$
$\mathrm{A}_{\mathrm{s} 2}=5.07 \cdot \mathrm{in}^{2}$
$\mathrm{M}_{\mathrm{LL}}:=(16 \cdot \mathrm{kip}) \cdot(0.5 \cdot \mathrm{L})$
$\mathrm{A}_{\mathrm{s} 1}:=\mathrm{A}_{\mathrm{s}}-\mathrm{A}_{\mathrm{s} 2}$
$\mathrm{A}_{\mathrm{s} 1}=3.88 \cdot \mathrm{in}^{2}$
$\mathrm{M}_{\mathrm{DL}}:=0.125 \cdot \mathrm{b} \cdot(\mathrm{h}) \cdot \gamma_{\mathrm{c}} \cdot \mathrm{L}^{2}$
$\varepsilon_{\mathrm{t}}:=\frac{\mathrm{d}-\mathrm{c}}{\mathrm{c}} \cdot 0.003$
$\varepsilon_{\mathrm{t}}=0.00952$
$\mathrm{M}_{\mathrm{LL}}=160 \cdot \mathrm{kip} \cdot \mathrm{ft}$
$\mathrm{M}_{\mathrm{DL}}=75 \cdot \mathrm{kip} \cdot \mathrm{ft}$ 
CheckTensionSteel $:=\operatorname{if}\left(\varepsilon_{\mathrm{t}}>0.005\right.$, "OK, Tension Steel Yielding Governs Failure" , No Good,Revise Section" $)$

CheckTensionSteel $=$ "OK, Tension Steel Yielding Governs Failure"

Applied bending moment per feet width of approach slab,

$$
\begin{aligned}
& \mathrm{M}_{\mathrm{u}}:=\frac{\left(1.25 \cdot \mathrm{M}_{\mathrm{DL}}+1.75 \cdot 1.33 \cdot 1.2 \cdot \mathrm{M}_{\mathrm{LL}}\right)}{\mathrm{b}} \\
& \mathrm{M}_{\mathrm{u}}=54.06 \cdot \mathrm{kip} \cdot \frac{\mathrm{ft}}{\mathrm{ft}}
\end{aligned}
$$

Internal moment capacity per feet width of approach slab,

$$
\begin{aligned}
\phi M_{n} & :=\frac{\phi \cdot\left[A_{s 1} \cdot f_{y} \cdot(d-0.5 \cdot a)+A_{s 2} \cdot f_{s} \cdot\left(d-d^{\prime}\right)\right]}{b} \\
\phi M_{n} & =21.87 \cdot \mathrm{kip} \cdot \frac{\mathrm{ft}}{\mathrm{ft}}
\end{aligned}
$$




\section{Moment calculations for Ohio DOT drawing}

\section{Beam dimension:}

$\mathrm{b}:=120 \cdot$ in

$\mathrm{h}:=15 \cdot$ in

$\mathrm{C}_{\mathrm{c}}:=3 \cdot$ in

$\mathrm{d}^{\prime}:=3 \cdot$ in

$\mathrm{d}:=\mathrm{h}-\mathrm{C}_{\mathrm{c}}$
Material properties:

$$
\begin{aligned}
& \mathrm{A}_{\mathrm{S}^{\prime}}:=2.1 \cdot \mathrm{in}^{2} \\
& \mathrm{~A}_{\mathrm{S}}:=21.77 \cdot \mathrm{in}^{2} \\
& \mathrm{~W}_{\mathrm{S}}:=1.75 \cdot \mathrm{in} \\
& \mathrm{L}_{M}:=25 \cdot \mathrm{ft}
\end{aligned}
$$

$$
\gamma_{\mathrm{c}}:=0.15 \cdot \frac{\mathrm{kip}}{\mathrm{ft}^{3}} \quad \mathrm{f}_{\mathrm{y}}:=60 \cdot \mathrm{ksi}
$$

$\mathrm{E}:=29000 \cdot \mathrm{ksi}$

$\mathrm{f}_{\mathrm{c}}:=4.5 \cdot \mathrm{ksi}$

$\phi:=0.9$

Assume

$$
\stackrel{c}{c}:=1 \cdot \text { in }
$$

Given

$$
\begin{aligned}
& A_{s} \cdot f_{y}=\left(0.85 \cdot f_{c} \cdot 0.825 \cdot c \cdot b\right)+A_{s^{\prime}} \cdot \frac{\left(c-d^{\prime}\right)}{c} \cdot 0.003 \cdot E \\
& \underset{M M}{c}:=\operatorname{Find}(\mathrm{c}) \\
& \mathrm{c}=3.39 \cdot \text { in } \\
& \mathrm{a}:=0.825 \cdot \mathrm{c} \\
& \mathrm{a}=2.8 \cdot \mathrm{in} \\
& \mathrm{f}_{\mathrm{S}^{\prime}}:=\frac{\left|\mathrm{c}-\mathrm{d}^{\prime}\right|}{\mathrm{c}} \cdot 0.003 \cdot \mathrm{E} \\
& \mathrm{f}_{\mathrm{s}^{\prime}}=10.09 \cdot \mathrm{ksi}
\end{aligned}
$$

CheckCompressionSteel $:=\operatorname{if}\left(\mathrm{f}_{\mathrm{s}^{\prime}}<\mathrm{f}_{\mathrm{y}}\right.$, "Compression Steel Not Yielding" , "Compression Steel Yielding" $)$

CheckCompressionSteel $=$ "Compression Steel Not Yielding"
$A_{\mathrm{s} 2}:=\frac{A_{s^{\prime}} \cdot f_{\mathrm{s}^{\prime}}}{f_{y}}$
$\mathrm{A}_{\mathrm{s} 2}=0.35 \cdot \mathrm{in}^{2}$
$\mathrm{M}_{\mathrm{LL}}:=(16 \cdot \mathrm{kip}) \cdot(0.5 \cdot \mathrm{L})$
$\mathrm{A}_{\mathrm{s} 1}:=\mathrm{A}_{\mathrm{s}}-\mathrm{A}_{\mathrm{s} 2}$
$\mathrm{A}_{\mathrm{s} 1}=21.42 \cdot \mathrm{in}^{2}$
$\mathrm{M}_{\mathrm{DL}}:=0.125 \cdot \mathrm{b} \cdot(\mathrm{h}) \cdot \gamma_{\mathrm{c}} \cdot \mathrm{L}^{2}$
$\varepsilon_{\mathrm{t}}:=\frac{\mathrm{d}-\mathrm{c}}{\mathrm{c}} \cdot 0.003$
$\varepsilon_{\mathrm{t}}=0.00761$
$\mathrm{M}_{\mathrm{LL}}=200 \cdot \mathrm{kip} \cdot \mathrm{ft}$
$\mathrm{M}_{\mathrm{DL}}=146.48 \cdot \mathrm{kip} \cdot \mathrm{ft}$ 
CheckTensionSteel $:=\operatorname{if}\left(\varepsilon_{\mathrm{t}}>0.005\right.$, "OK, Tension Steel Yielding Governs Failure" , No Good,Revise Section" $)$

CheckTensionSteel $=$ "OK, Tension Steel Yielding Governs Failure"

Applied bending moment per feet width of approach slab,

$$
\mathrm{M}_{\mathrm{u}}:=\frac{\left(1.25 \cdot \mathrm{M}_{\mathrm{DL}}+1.75 \cdot 1.33 \cdot 1.2 \cdot \mathrm{M}_{\mathrm{LL}}\right)}{\mathrm{b}} \quad \mathrm{M}_{\mathrm{u}}=74.17 \cdot \mathrm{kip} \cdot \frac{\mathrm{ft}}{\mathrm{ft}}
$$

Internal moment capacity per feet width of approach slab,

$$
\begin{aligned}
& \phi \mathrm{M}_{\mathrm{n}}:=\frac{\phi \cdot\left[\mathrm{A}_{\mathrm{s} 1} \cdot \mathrm{f}_{\mathrm{y}} \cdot(\mathrm{d}-0.5 \cdot \mathrm{a})+\mathrm{A}_{\mathrm{s} 2} \cdot \mathrm{f}_{\mathrm{s}} \cdot\left(\mathrm{d}-\mathrm{d}^{\prime}\right)\right]}{\mathrm{b}} \\
& \phi \mathrm{M}_{\mathrm{n}}=102.4 \cdot \mathrm{kip} \cdot \frac{\mathrm{ft}}{\mathrm{ft}}
\end{aligned}
$$




\section{Moment calculations for Pennsylvania DOT drawing}

\section{Beam dimension:}

$\mathrm{b}:=120 \cdot$ in

$\mathrm{h}:=16 \cdot$ in

$\mathrm{C}_{\mathrm{c}}:=3 \cdot$ in

$\mathrm{d}^{\prime}:=2.5 \cdot$ in

$\mathrm{d}:=\mathrm{h}-\mathrm{C}_{\mathrm{c}}$
Material properties:

$$
\begin{aligned}
& \mathrm{A}_{\mathrm{S}^{\prime}}:=3.1 \cdot \mathrm{in}^{2} \\
& \mathrm{~A}_{\mathrm{S}}:=16.93 \cdot \mathrm{in}^{2} \\
& \mathrm{~W}_{\mathrm{S}}:=1.75 \cdot \mathrm{in} \\
& \mathrm{L}_{M}:=25 \cdot \mathrm{ft}
\end{aligned}
$$

$\phi:=0.9$ $\gamma_{\mathrm{c}}:=0.15 \cdot \frac{\mathrm{kip}}{\mathrm{ft}^{3}} \quad \mathrm{f}_{\mathrm{y}}:=60 \cdot \mathrm{ksi}$

$\mathrm{E}:=29000 \cdot \mathrm{ksi} \quad \mathrm{f}_{\mathrm{c}}:=3.5 \cdot \mathrm{ksi}$

Assume

$$
\underset{M M}{c}:=1 \cdot \text { in }
$$

Given

$$
\begin{array}{ll}
\mathrm{A}_{\mathrm{s}} \cdot \mathrm{f}_{\mathrm{y}}=\left(0.85 \cdot \mathrm{f}_{\mathrm{c}} \cdot 0.85 \cdot \mathrm{c} \cdot \mathrm{b}\right)+\mathrm{A}_{\mathrm{s}^{\prime}} \cdot \frac{\left(\mathrm{c}-\mathrm{d}^{\prime}\right)}{\mathrm{c}} \cdot 0.003 \cdot \mathrm{E} \\
\underset{M \mathrm{M}^{\mathrm{c}}:=\text { Find }(\mathrm{c})}{\mathrm{c}=3.16 \cdot \mathrm{in}} \\
\mathrm{a}:=0.85 \cdot \mathrm{c} & \mathrm{a}=2.69 \cdot \mathrm{in} \\
\mathrm{f}_{\mathrm{s}^{\prime}}:=\frac{\left|\mathrm{c}-\mathrm{d}^{\prime}\right|}{\mathrm{c}} \cdot 0.003 \cdot \mathrm{E} & \mathrm{f}_{\mathrm{s}^{\prime}}=18.2 \cdot \mathrm{ksi}
\end{array}
$$

CheckCompressionSteel $:=\operatorname{if}\left(\mathrm{f}_{\mathrm{s}^{\prime}}<\mathrm{f}_{\mathrm{y}}\right.$, "Compression Steel Not Yielding" , "Compression Steel Yielding" $)$

CheckCompressionSteel $=$ "Compression Steel Not Yielding"
$A_{\mathrm{s} 2}:=\frac{A_{s^{\prime}} \cdot f_{\mathrm{s}^{\prime}}}{f_{y}}$
$\mathrm{A}_{\mathrm{s} 2}=0.94 \cdot \mathrm{in}^{2}$
$\mathrm{M}_{\mathrm{LL}}:=(16 \cdot \mathrm{kip}) \cdot(0.5 \cdot \mathrm{L})$
$\mathrm{A}_{\mathrm{s} 1}:=\mathrm{A}_{\mathrm{s}}-\mathrm{A}_{\mathrm{s} 2}$
$\mathrm{A}_{\mathrm{s} 1}=15.99 \cdot \mathrm{in}^{2}$
$\mathrm{M}_{\mathrm{DL}}:=0.125 \cdot \mathrm{b} \cdot(\mathrm{h}) \cdot \gamma_{\mathrm{c}} \cdot \mathrm{L}^{2}$
$\varepsilon_{\mathrm{t}}:=\frac{\mathrm{d}-\mathrm{c}}{\mathrm{c}} \cdot 0.003$
$\varepsilon_{\mathrm{t}}=0.00934$

$\mathrm{M}_{\mathrm{LL}}=200 \cdot \mathrm{kip} \cdot \mathrm{ft}$
$\mathrm{M}_{\mathrm{DL}}=156.25 \cdot \mathrm{kip} \cdot \mathrm{ft}$ 
CheckTensionSteel $:=\operatorname{if}\left(\varepsilon_{\mathrm{t}}>0.005\right.$, "OK, Tension Steel Yielding Governs Failure" , "No Good,Revise Section" $)$

CheckTensionSteel = "OK, Tension Steel Yielding Governs Failure"

Applied bending moment per feet width of approach slab,

$$
\mathrm{M}_{\mathrm{u}}:=\frac{\left(1.25 \cdot \mathrm{M}_{\mathrm{DL}}+1.75 \cdot 1.33 \cdot 1.2 \cdot \mathrm{M}_{\mathrm{LL}}\right)}{\mathrm{b}} \quad \mathrm{M}_{\mathrm{u}}=75.39 \cdot \mathrm{kip} \cdot \frac{\mathrm{ft}}{\mathrm{ft}}
$$

Internal moment capacity per feet width of approach slab,

$$
\begin{aligned}
\phi \mathrm{M}_{\mathrm{n}} & :=\frac{\phi \cdot\left[\mathrm{A}_{\mathrm{s} 1} \cdot \mathrm{f}_{\mathrm{y}} \cdot(\mathrm{d}-0.5 \cdot \mathrm{a})+\mathrm{A}_{\mathrm{s} 2} \cdot \mathrm{f}_{\mathrm{s}} \cdot\left(\mathrm{d}-\mathrm{d}^{\prime}\right)\right]}{\mathrm{b}} \\
\phi \mathrm{M}_{\mathrm{n}} & =85.22 \cdot \mathrm{kip} \cdot \frac{\mathrm{ft}}{\mathrm{ft}}
\end{aligned}
$$

